\title{
Molecular mechanisms in the developmental regulation of the maize Suppressor-mutator transposable element
}

\author{
Jo Ann Banks, Patrick Masson, and Nina Fedoroff \\ Department of Embryology, Carnegie Institution of Washington, Baltimore, Maryland 21210 USA
}

The maize Suppressor-mutator (Spm) element can exist in one of three heritable forms: (1) a stably active form, (2) a stably inactive form, termed cryptic, and (3) a labile form, here termed programmable, in which the element exhibits one of a variety of heritable developmental programs of expression. Active elements are transcribed and are hypomethylated at sites upstream of the transcription start site, whereas inactive elements are transcriptionally silent and largely methylated at the upstream sites. Active (both stable and programmable), inactive programmable, and cryptic elements are unmethylated, partially methylated, and fully methylated, respectively, at sites within an $0.35-\mathrm{kb} 80 \% \mathrm{G}+\mathrm{C}$ region just downstream from the transcription start site. An active Spm element in a genome with a cryptic element promotes its partial demethylation but not its transcriptional activation. In contrast, a trans-acting Spm promotes extensive demethylation and transcriptional activation of an inactive programmable element, as well as its heritable reactivation. These observations define the molecular components of the Spm element's developmental regulatory mechanism. We discuss their general relevance to the developmental regulation of gene expression.

[Key Words: Maize; transposable elements; Suppressor-mutator; methylation, transcriptional activation; developmental regulation]

Received July 7, 1988; revised version accepted September 19, 1988.

A striking and poorly understood property of maize transposable elements is that both element expression and the timing and frequency of element transposition are developmentally regulated. The early genetic studies of McClintock on the Suppressor-mutator (Spm) element and Peterson on the cognate Enhancer (En) element established the existence of several heritable, but interconvertible, forms of the Spm element (McClintock 1957, 1958, 1959, 1965a,b; Peterson 1966; Fowler and Peterson 1978). These include the cryptic form, in which the element is genetically silent. Both McClintock and Peterson also identified elements that were capable of undergoing reversible transitions between the active and inactive phases in a characteristic and heritable pattern during development (McClintock 1957, 1958, 1962, 1965a,b, 1971; Peterson 1966; Fowler and Peterson 1978). We showed recently that the genetic mechanism responsible for the developmental control of Spm expression has two components, which we designated the phase setting and the phase program (Fedoroff and Banks 1988). The phase setting determines whether the element is genetically active or inactive. The phase program determines the heritability of the phase setting, as well as when, where, and how frequently it will be reversed during plant development. The underlying genetic mechanism is heritable, reversible, and capable of promoting the incremental transition of the element from a stably active to a stably inactive (cryptic) form, implying the involvement of multiple epigenetic events (Fedoroff and Banks 1988). In view of the accumulating evidence that the inactivation of gene expression, in general (for reviews, see Razin et al. 1984; Adams and Burdon 1985; Holliday 1987; Cedar 1988), and maize transposable elements, in particular (Fedoroff et al. 1983; Bennetzen 1985; Chandler and Walbot 1986; Schwartz and Dennis 1986; Chomet et al. 1987; Fedoroff et al. $1988 \mathrm{a}, \mathrm{b}$ ), are associated with DNA modification, we have investigated the relationship between Spm expression and the methylation pattern of sequences within and flanking an Spm element inserted at the maize $a$ locus.

We studied three genetically distinguishable forms of the Spm element. These are the stably active form and the stably inactive form, termed cryptic. The third form is a labile one, here designated programmable, in which the element can be either in the active or inactive phase and can readily be both reset and reprogrammed $(\mathrm{Fe}$ doroff and Banks 1988). We show that all three forms of the Spm element are methylated throughout most of the element's $8.3-\mathrm{kb}$ sequence but the flanking a-gene sequences are not methylated. Spm elements in the three different forms can be distinguished by the pattern of cytosine methylation immediately upstream and downstream from the element's transcription start site. Be- 
cause there is genetic evidence that an inactive programmable Spm, but not a cryptic Spm, can be trans-activated by a second, active Spm element present in the same genome, we investigated the effect of the trans-activating element on the expression and methylation of inactive elements. The abundance of element-homologous transcripts is elevated markedly by a weakly active Spm (Spm-w) in a plant containing an inactive programmable element but not in one with a cryptic Spm. Both inactive programmable and cryptic elements show reduced methylation at the $5^{\prime}$ end in the presence of an $S p m-w$ element. In addition, the Spm- $w$ promotes heritable reactivation of an inactive programmable element.

\section{Results}

Active, cryptic, and programmable Spm elements

The genetic properties of the Spm insertion alleles used in the present study have been described elsewhere in detail and are recounted here only briefly. All are derivatives of McClintock's original $a-m 2$ allele, in which a standard Spm element (Spm-s) inserted just upstream of the $a$ gene (McClintock 1951, 1962; Masson et al. 1987; Fedoroff and Banks 1988). As illustrated in Figure 1, the element's transcription unit, which commences within $0.2 \mathrm{~kb}$ of the element's left $\left(5^{\prime}\right)$ terminus, is opposite in orientation to that of the $a$ gene (Pereira et al. 1986;
Masson et al. 1987; Schwarz-Sommer et al. 1987). Figure 2 , $a$ and b, shows the kernel phenotypes of the active form of the two alleles used here. They are designated the $a-m 2-8167 B$ (reactivated) and $a-m 2-7991 A 1$ alleles. Kernels carrying either allele exhibit a relatively uniform pale background pigmentation due to a low level of expression of the adjacent $a$ gene, which encodes an enzyme in the anthocyanin pigment biosynthetic pathway (Coe and Neuffer 1977). The two alleles differ phenotypically in the density of the variegation pattern, which is a function of the frequency and timing of element excision during kernel development (for further details, see Methods). The aleurone phenotype of both alleles is colorless when the resident Spm element is genetically inactive or transposition defective (Fig. 2c). There are no pigmented revertant sectors because the inserted element is not excised from the $a$ locus, and there is no background pigmentation because the $a$ gene is not expressed. Although phenotypically indistinguishable, an inactive element differs from a mutant element by its ability to return to the original active phase (McClintock 1962; Masson et al. 1987). Reactivation of the element is marked by both the reappearance of background pigmentation due to $S p m$-dependent a-gene expression and variegation attributable to somatic excision of the element (Fig. 2d,e).

The difference between the cryptic and programmable forms of the element resides in the developmental and

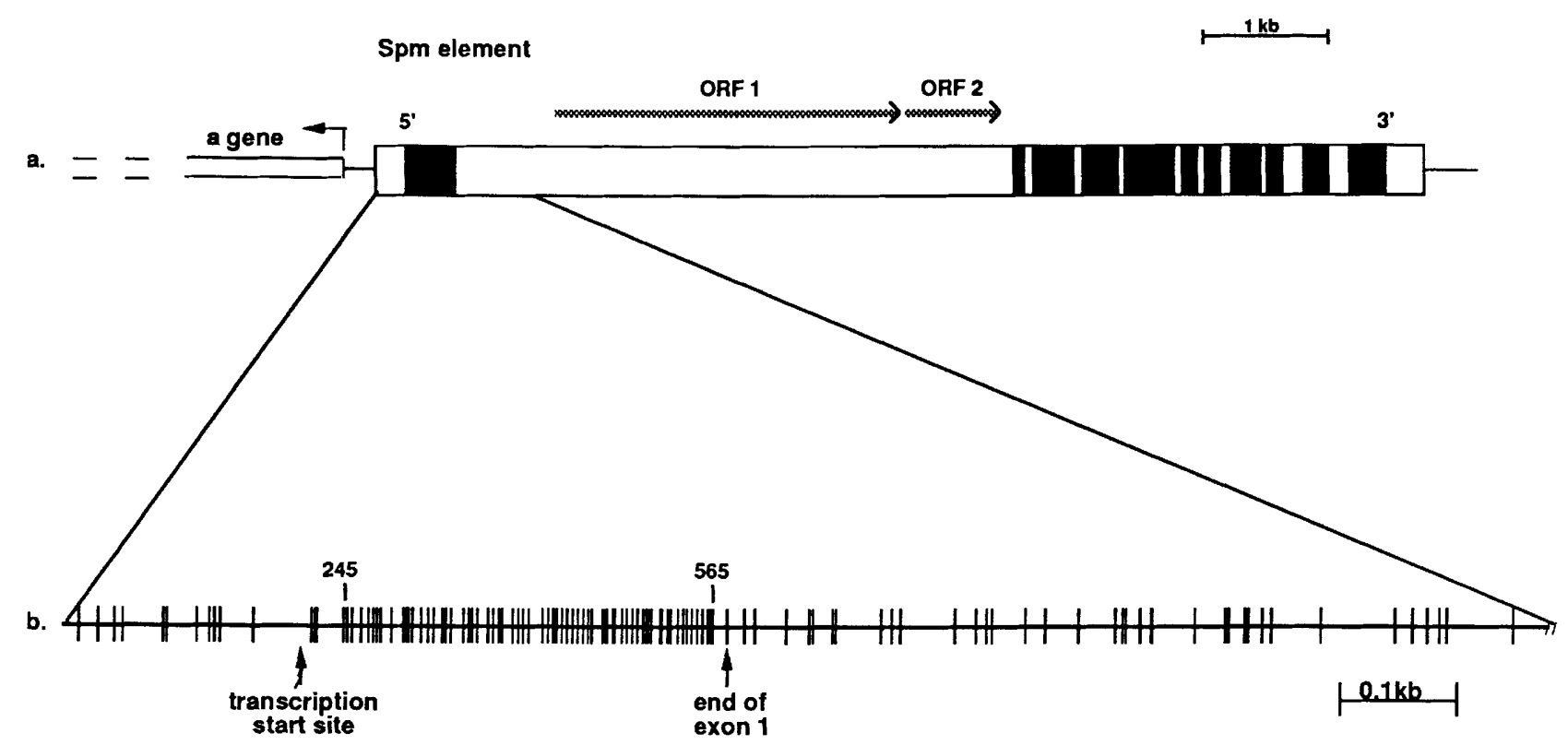

Figure 1. The structure and sequence organization of the Spm element. (a) A diagrammatic representation of the Spm element and its relationship to the $a$ gene in the $a-m 2$ alleles. The $8.3-\mathrm{kb} S p m$ element is inserted at a site $0.1 \mathrm{~kb}$ upstream of the transcription start site at the $a$ locus (Schwarz-Sommer et al. 1987). The $a$ gene and element are transcribed divergently. The solid areas of the Spm element represent the exons of its major 2.5-kb transcript (Pereira et al. 1986; Masson et al. 1987). The arrows above the element represent the open reading frames (ORFs) within its large intron. (b) A diagrammatic representation of the location of methylatable $\mathrm{C}$ residues at the $5^{\prime}$ end of the element. Each vertical bar corresponds to the location of either a CG dinucleotide or CNG trinucleotide sequence. 

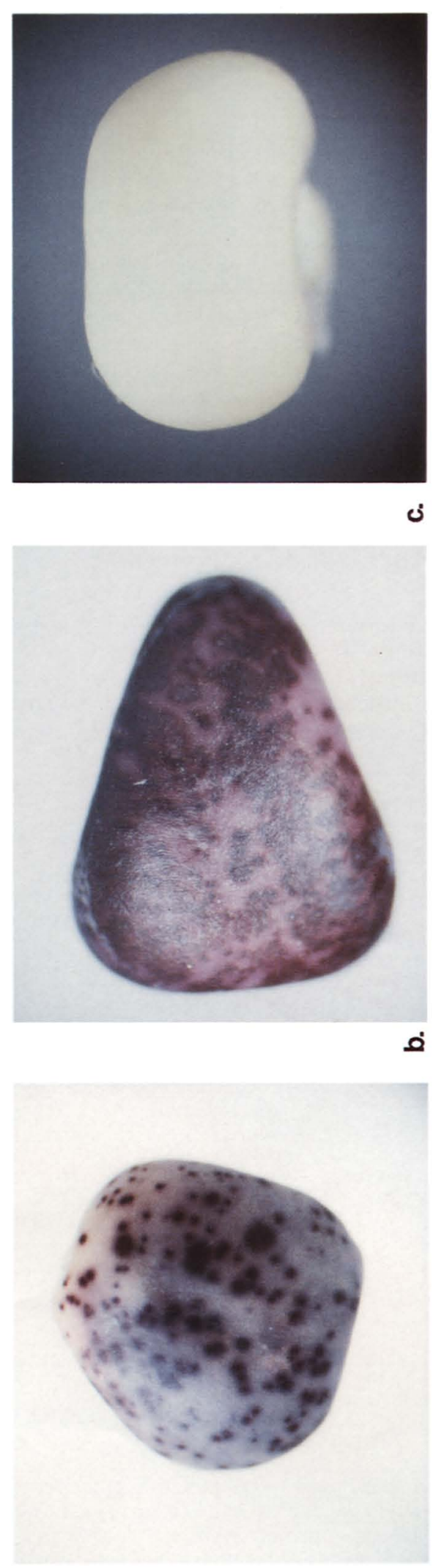

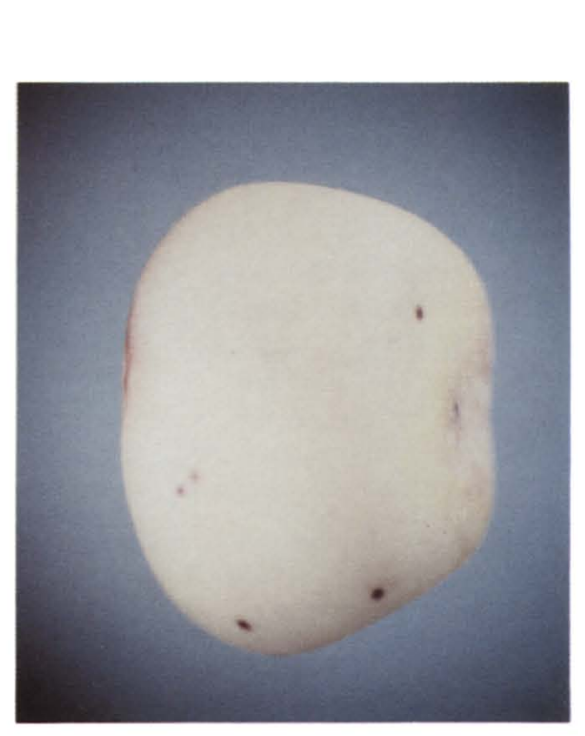

路自

욤

वे क

ฐิ

苞

을

एँ

要

घำ

कू

ธิ

चี

그

흐을

궁

สิ

वे के

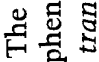

- 可峁

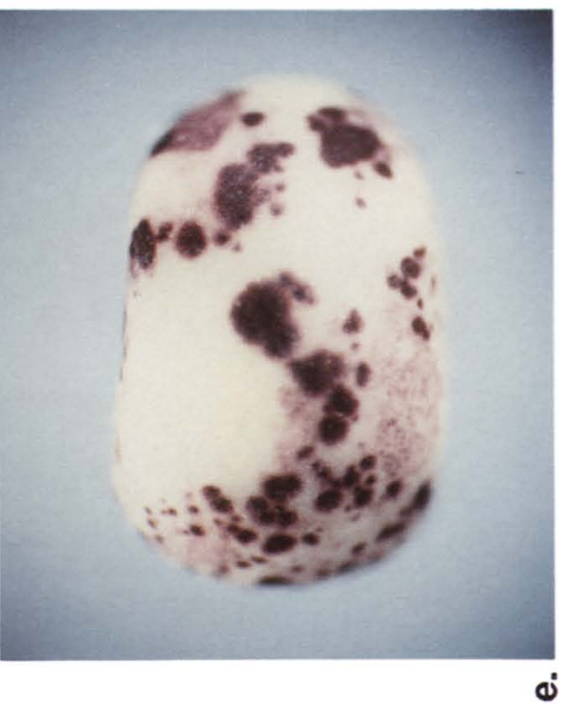

高

농

पर

몽

प. 50

북

E

कำ

政

ह

조

중

की

ข่

3 है

过

옾

万人

है ?

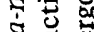
. 范 造密 要 ठ․ \% $\square$. 远 월 ำ ส ำ चे (1) 음 क्ष : 要 등 \& 政 政 可

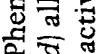
. ㄱ.

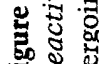


hereditary stability of the element's phase setting. The allele with the cryptic element that we have used is designated the $a-m 2-8167 B$ (cryptic) allele (Masson et al. 1987). As shown in Table 1, the allele is extremely stable. None of the 25,435 kernels examined exhibited spontaneous excision of the resident Spm element. The capacity of the resident element to be excised by a transacting Spm element is low, as is its ability to mediate activation of the adjacent $a$ gene (Fig. 2f). The Spm element in this allele was originally identified as transposition defective, but it was found to be structurally indistinguishable from a standard Spm (Spm-s) element (Masson et al. 1987). Recently, we have succeeded in genetically reactivating the resident element (Fig. 2a; for details, see Methods|, demonstrating that the element is functionally, as well as structurally, intact. We redesignated the element as cryptic to denote that its state of inactivity is exceedingly stable but that the element is nonetheless capable of returning to a fully functional state.

Inactive Spm elements in the programmable form exhibit a much lower genetic stability of the phase setting than does a cryptic Spm element (Masson et al. 1987; Fedoroff and Banks 1988). Moreover, the stability of the phase setting differs markedly among different deriva- tives and depends on the plant part and sex of the gamete that transmits the element to the progeny $(\mathrm{Fe}$ doroff and Banks 1988). Table 1 gives illustrative data for two inactive derivatives of the $a-m 2-7991 A 1$ allele that are in the programmable form. The two lineages originated from different kernels produced on a single plant and showed differences in the frequency of element reactivation that persisted through three generations of plants (Fedoroff and Banks 1988). It is evident from even the limited amount of data shown in Table 1 that there are marked differences in the heritability of the inactive state upon transmission of the element to progeny through male and female gametes, as well as the gametes produced on the plant's main stalk and its tillers.

The Spm element is methylated extensively, but the a gene is not

Because the results of genetic studies on both cryptic and programmable forms of the element indicate that the phase setting is both heritable and reversible, we examined the accessibility of each element form to digestion with restriction enzymes that cannot cut $\mathrm{C}$-methylated cleavage sites (Kessler and Holtke 1986). The general design of the experiments is illustrated by the

Table 1. Stability of the inactive phase in cryptic and programmable Spm elements

\begin{tabular}{|c|c|c|c|c|c|c|c|}
\hline & & & & \multicolumn{4}{|c|}{ B. Inactive programmable Spma } \\
\hline \multicolumn{4}{|c|}{ A. Cryptic Spm } & \multicolumn{2}{|c|}{ lineage 1} & \multicolumn{2}{|c|}{ lineage 2} \\
\hline Parent & $\begin{array}{l}\text { Gamete } \\
\text { source }\end{array}$ & $\begin{array}{l}\text { Total } \\
\text { no. of } \\
\text { kernels }\end{array}$ & $\begin{array}{l}\text { Fully } \\
\text { active Spm } \\
(\%)\end{array}$ & $\begin{array}{l}\text { Total } \\
\text { no. of } \\
\text { kernels }\end{array}$ & $\begin{array}{l}\text { Fully } \\
\text { active Spm } \\
(\%)\end{array}$ & $\begin{array}{l}\text { Total } \\
\text { no. of } \\
\text { kernels }\end{array}$ & $\begin{array}{l}\text { Fully } \\
\text { active Spm } \\
(\%)\end{array}$ \\
\hline$q$ & ear I & 2633 & 0 & 4751 & 3.5 & $\begin{array}{l}\mathrm{A}^{\mathrm{b}} 1030 \\
\mathrm{~B}^{\mathrm{b}} 1878\end{array}$ & $\begin{array}{l}39.4 \\
19.9\end{array}$ \\
\hline & ear II & - & - & 4036 & 3.9 & $\begin{array}{ll}\text { A } & 529 \\
\text { B } & 405\end{array}$ & $\begin{array}{l}56.0 \\
43.0\end{array}$ \\
\hline & tiller & 3038 & 0 & 2920 & 39.0 & $\begin{array}{cl}\text { A } & 593 \\
\text { B } & 164\end{array}$ & $\begin{array}{l}54.3 \\
90.2\end{array}$ \\
\hline 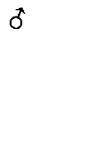 & $\begin{array}{l}\text { mainstalk } \\
\text { tiller }\end{array}$ & $19,764^{\mathrm{c}}$ & 0 & $\begin{array}{l}3500 \\
6130\end{array}$ & $\begin{array}{r}1.6 \\
21.7\end{array}$ & $\begin{array}{cr}\text { A } & 866 \\
\text { B } & 681 \\
\text { A } & 1786 \\
\text { B } & 2641\end{array}$ & $\begin{array}{l}32.2 \\
19.7 \\
61.8 \\
50.5\end{array}$ \\
\hline
\end{tabular}

${ }^{a}$ Lineages 1 and 2 in $B$ were derived from a single parent plant but from progeny plants grown from different kernels. The numbers reported in lineages 1 and 2 are taken from the families designated 2195 and 2199, analyzed in detail in Fedoroff and Banks (1988). All of the plants in families were grown from kernels with a completely or almost completely inactive Spm element. The two parent ears from which the kernels were selected gave $46.5 \%$ (lineage 1) and $10 \%$ (lineage 2) of kernels with an inactive Spm element. Progeny of these plants were examined for the fraction of kernels showing variegation throughout the aleurone layer of the kernels, indicating that the element transmitted through the gamete in question was in the fully active state. The results are given separately for elements transmitted through female gametes produced on the main stalk (ear I, ear II) and tillers and transmitted through male gametes produced on the main stalk and tillers, except for the cryptic element.

${ }^{b} \mathrm{~A}$ and B plants were grown from kernels that showed no Spm activity and one or two revertant sectors, respectively, indicating almost no Spm activity.

c Among 19,764 gametes tested in outcrosses, 4 kernels receiving the Spm element showed variegation throughout the kernel. Because the Spm parent was heterozygous for the $a$ allele containing the inactive Spm and an allele with a $d S p m$ element $[a-m 2-8167 B$ (cryptic) Sh2/a-ml-5719A1 sh2], each test cross onto a plant that was homozygous for the $a$ and sh2 alleles produced equal numbers of kernels that did and did not receive an inactive Spm element. Among those kernels that received the $d S p m$ tester allele $\mid a-m l-$ $5719 A 1)$, there were also four fully variegated kernels. This observation, together with the fact that the phenotype of the Sh2 variegated kernels was that of the original $a-m 2-8167 B$ (cryptic) allele (Fig. 2f), rather than that of the fully reactivated element at the $a$ locus (Fig. 2a), indicates that the variegated kernels were attributable to activation of silent Spm elements in the tester parent, rather than spontaneous reactivation of the cryptic element in the a-m2-8167B (cryptic) allele. 
Figure 3. Methylation of the PvuII and PstI sites within and adjacent to the Spm element. (A) The location of the methylation-sensitive PvuII, PstI, and SmaI restriction sites and the methylation-insensitive BamHI sites within the Spm element and $a$ gene. To assess the methylation state of the PvuII sites, genomic DNA was isolated from plants containing either programmable (active and inactive) or cryptic Spm elements, digested with PvuII and SmaI, and hybridized with the a-gene probe shown in $A$. Fragments with homology to the probe that can be produced by digestion with PvuII and SmaI are shown. To assess methylation of the PstI sites, $3.8-\mathrm{kb}$ BamHI fragments were gel purified from BamHI-digested genomic DNA samples, then digested with PstI, and hybridized to the $a$ gene probe shown. (Bottom) The fragments homologous to the probe that will be produced, depending on the methylation state of the various PstI sites. (B) Results of a blot hybridization experiment to determine methylation of the PvuII sites. Digestion of genomic DNA with SmaI alone yields a 9.8-kb fragment homologous to the a-gene probe, indicating that the SmaI sites flanking the Spm elements are cleaved (not shown). The 2.4-kb fragment in each lane corresponds to the $a$ allele present on the homolog in each plant. $(C)$ Results of a blot hybridization experiment to assess methylation of the PstI sites. (1) Uncleaved, methylation-sensitive restriction site $(O)$ cleaved, methylation-sensitive restriction site; $(\varnothing)$ cleaved, methylation-insensitive restriction site. $(\mathrm{Bm})$ BamHI; (P) PstI; (Pv) PvuII; (Sm) SmaI.
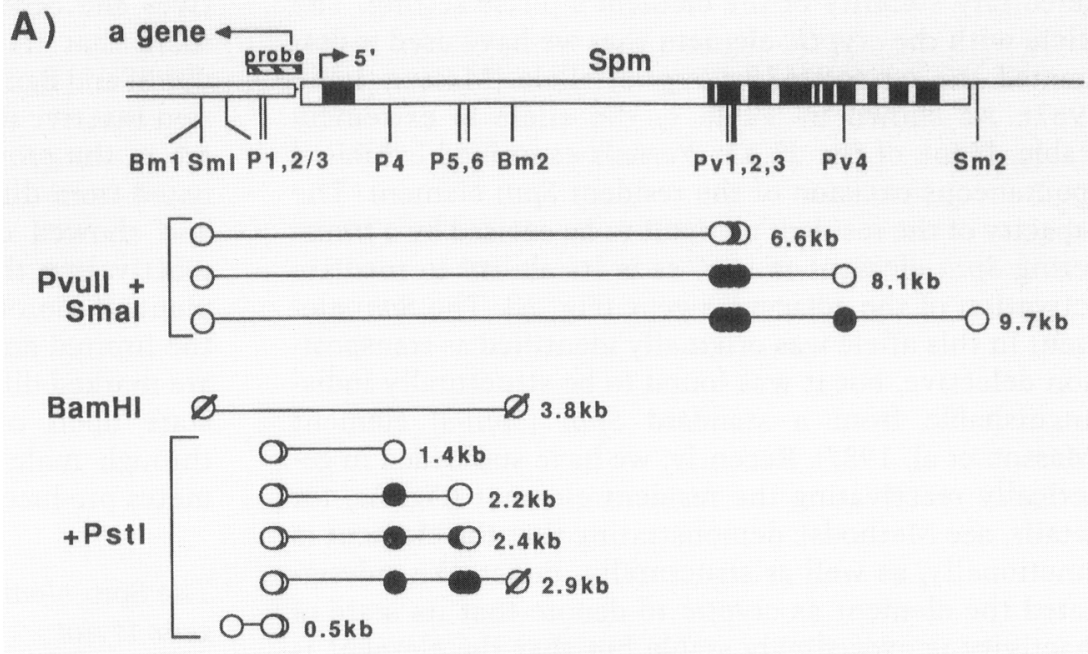

B)

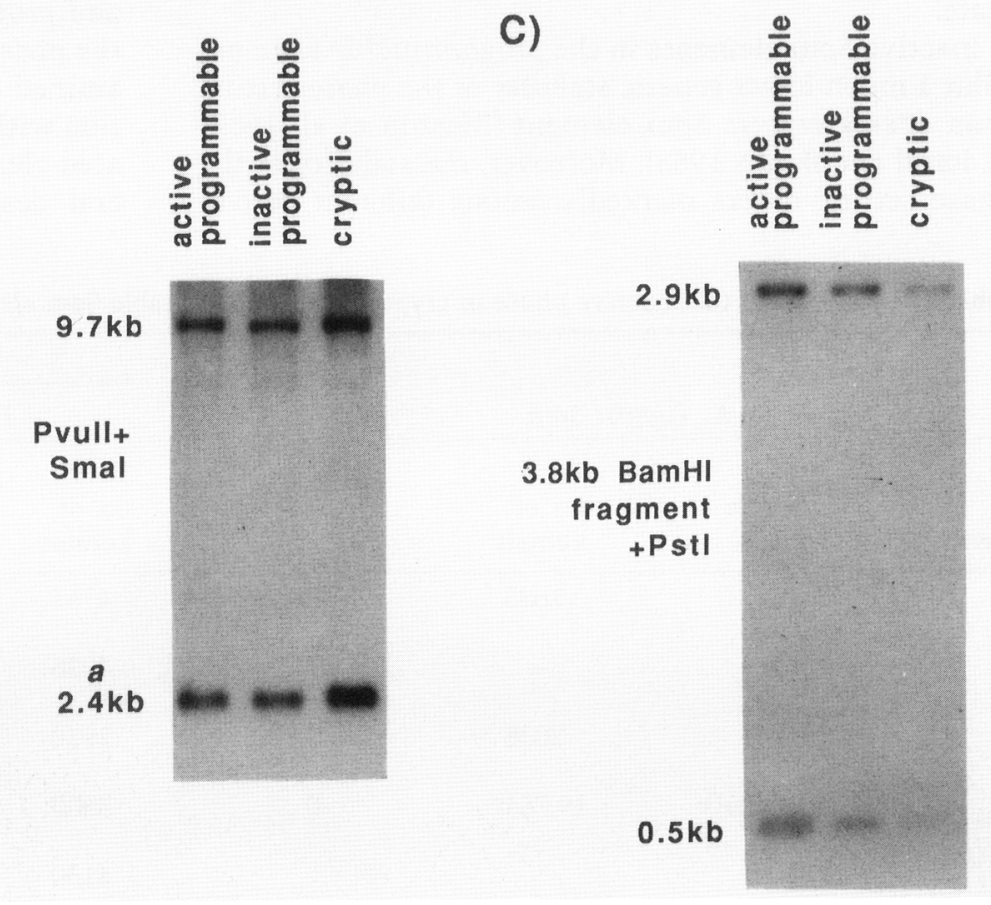

diagram shown in Figure $3 \mathrm{~A}$. The observed fragments are those expected if the methylation-sensitive sites in the $a$-locus sequence are sensitive to cleavage. If the enzyme used has cleavage sites within the element, but at a distance of more than $1 \mathrm{~kb}$ from the end containing its transcription initiation site, the observed fragments are those expected if all of the sites are methylated and therefore resistant to digestion. This is true both for enzymes inhibited by the methylation of the $\mathrm{C}$ residue in the dinucleotide CG and for those inhibited by methylation of the $\mathrm{C}$ residue in the trinucleotide CNG, which is commonly methylated in plant DNA (Gruenbaum et al. 1981). Representative blots illustrating the outcome of such experiments with the restriction endonucleases PstI and PvuII are shown in Figure 3B. All of the results are reported in Table 2 and represented diagrammati- cally in Figure 6. The data show that most methylatable $C$ residues are methylated in the element, but not in the flanking $a$ locus sequence, regardless of the element's phase of activity.

Active, cryptic, and inactive programmable forms of the Spm differ in the extent of methylation at the element's 5 ' end

As originally noted by Pereira et al. (1986) for the cognate Enhancer $(E n)$ element, there is a markedly GC-rich sequence near the element's $5^{\prime}$ end, commencing just on the $3^{\prime}$ side of its transcription initiation site at nucleotide 209. The diagram in Figure $1 \mathrm{~b}$ highlights the high density of methylatable CG dinucleotides and CNG trinucleotides between 245 and 565 bp from the ele- 
Table 2. Restriction fragments comprising part of the a gene and inserted Spm element obtained after digestion of genomic DNA with methylation-sensitive and methylation-insensitive restriction enzymes

\begin{tabular}{|c|c|c|c|c|c|c|c|}
\hline \multirow[b]{2}{*}{ Enzymes } & \multirow[b]{2}{*}{$\begin{array}{l}\text { Possible } \\
\text { fragment } \\
\text { lengths }(\mathrm{kb})^{\mathrm{a}}\end{array}$} & \multicolumn{6}{|c|}{ Observed fragment lengths (kb) } \\
\hline & & Active & $\begin{array}{l}\text { Active } \\
\text { programmable }\end{array}$ & $\begin{array}{l}\text { Inactive } \\
\text { programmable }\end{array}$ & $\begin{array}{l}\text { Inactive } \\
\text { programmable } \\
+ \text { Spm-weak }\end{array}$ & Cryptic & $\begin{array}{l}\text { Cryptic } \\
+ \text { Spm-weak }\end{array}$ \\
\hline \multirow[t]{5}{*}{ PvuII + SmaI } & $6.6 \mathrm{Sml}, \mathrm{Pvl}$ & & & & & & \\
\hline & $6.6 \mathrm{Sml}, \mathrm{Pvl}, 2$ & & & & & & \\
\hline & $6.6 \mathrm{Sml}, \underline{\mathrm{Pvl}}, 2,3$ & & & & & & \\
\hline & $8.1 \mathrm{Sm} 1, \overline{\mathrm{Pv} 1}, \underline{2}, 3,4$ & & & & & & \\
\hline & $9.7 \mathrm{Sm} 1, \overline{\mathrm{Pv} 1}, 2,3,4, \mathrm{Sm} 2$ & 9.7 & 9.7 & 9.7 & 9.7 & 9.7 & 9.7 \\
\hline \multirow[t]{5}{*}{ PstI + BamHI } & $0.5 \mathrm{Pl}, 2 / 3$ & 0.5 & 0.5 & 0.5 & 0.5 & 0.5 & $\mathrm{ND}$ \\
\hline & $1.4 \mathrm{P} 2 / 3,4$ & & & & & & ND \\
\hline & $2.2 \mathrm{P} 2 / 3,4,5$ & & & & & & ND \\
\hline & $2.4 \mathrm{P} 2 / 3, \underline{4}, 5,6$ & & & & & & ND \\
\hline & $2.9 \mathrm{P} 2 / 3, \underline{4}, \underline{5}, 6, \mathrm{Bm} 2$ & 2.9 & 2.9 & 2.9 & 2.9 & 2.9 & $\mathrm{ND}$ \\
\hline \multirow[t]{3}{*}{ PstI $+\underline{\text { ScaI }}$} & $0.5 \mathrm{P} 1,2 / 3$ & ND & 0.5 & 0.5 & 0.5 & 0.5 & ND \\
\hline & $1.4 \mathrm{P} 2 / 3,4$ & ND & & & & & ND \\
\hline & $1.5 \mathrm{P} 2 / 3,4, \mathrm{Scl}$ & ND & 1.5 & 1.5 & 1.5 & 1.5 & ND \\
\hline \multirow[t]{3}{*}{ PstI + EcoRI } & $0.5 \mathrm{P} 1,2 / 3$ & ND & 0.5 & 0.5 & 0.5 & 0.5 & ND \\
\hline & $1.4 \mathrm{P} 2 / 3,4$ & ND & & & & & ND \\
\hline & $1.9 \mathrm{P} 2 / 3,4, \mathrm{R} 1$ & ND & 1.9 & 1.9 & 1.9 & 1.9 & ND \\
\hline \multirow[t]{5}{*}{ PstI + SmaI } & $0.5 \mathrm{P} 1,2 / \overline{3}$ & 0.5 & 0.5 & 0.5 & 0.5 & 0.5 & 0.5 \\
\hline & $1.4 \mathrm{P} 2 / 3,4$ & & & & & & \\
\hline & $2.2 \mathrm{P} 2 / 3,4,5$ & & & & & & \\
\hline & $2.4 \mathrm{P} 2 / 3, \underline{4}, \underline{5}, 6$ & & & & & & \\
\hline & $8.7 \mathrm{P} 2 / 3, \underline{4}, \underline{5}, \underline{6}, \mathrm{Sm} 2$ & 8.7 & 8.7 & 8.7 & 8.7 & 8.7 & 8.7 \\
\hline \multirow[t]{2}{*}{$A v a \mathrm{I}+\underline{\text { EcoRI }}$} & $1.8 \mathrm{Al}, 2$ & ND & 1.8 & 1.8 & 1.8 & & ND \\
\hline & $2.8 \mathrm{~A} 1,2, \mathrm{RI}$ & ND & & 2.8 & & 2.8 & ND \\
\hline \multirow[t]{2}{*}{ AvaI + BamHI } & $1.8 \mathrm{Bm} 1 / \mathrm{A} 1,2$ & 1.8 & 1.8 & 1.8 & 1.8 & & ND \\
\hline & $3.8 \mathrm{~A} 1,2, \mathrm{Bm} 2$ & & & 3.8 & & 3.8 & ND \\
\hline \multirow[t]{3}{*}{ SalI $+\underline{\text { BamHI }}$} & $1.1 \mathrm{Sl}, 2$ & 1.1 & 1.1 & 1.1 & 1.1 & & 1.1 \\
\hline & $3.2 \mathrm{Sl}, 2,3$ & & & & & & \\
\hline & $3.4 \mathrm{~S} 1, \underline{2}, \underline{3}, \mathrm{Bm} 2$ & & & 3.4 & 3.4 & 3.4 & 3.4 \\
\hline \multirow[t]{3}{*}{ SalI + SmaI } & $1.1 \mathrm{Sl}, 2$ & ND & 1.1 & 1.1 & 1.1 & & ND \\
\hline & $3.2 \mathrm{~S} 1,2,3$ & $\mathrm{ND}$ & & & & & ND \\
\hline & $9.2 \mathrm{~S} 1,2,3, \mathrm{Sm} 2$ & ND & & 9.2 & & 9.2 & ND \\
\hline \multirow{5}{*}{$\begin{array}{l}\text { SalI }+ \text { KpnI } \\
+\underline{\text { ScaI }} \\
\text { AvaI }+ \text { SalI } \\
+ \text { SmaI }\end{array}$} & $1.1 \mathrm{~S} 1,2$ & $\mathrm{ND}$ & 1.1 & 1.1 & ND & & ND \\
\hline & $2.0 \mathrm{~S} 1,2, \mathrm{ScI}$ & $\mathrm{ND}$ & & 2.0 & ND & 2.0 & ND \\
\hline & $1.1 \mathrm{~S} 1, \mathrm{~S} 2$ & 1.1 & 1.1 & 1.1 & 1.1 & & ND \\
\hline & $1.3 \mathrm{~S} 1,2, \mathrm{~A} 2$ & & & 1.3 & & & ND \\
\hline & $9.2 \mathrm{~S} 1, \underline{2}, \underline{3}, \mathrm{Sm} 2$ & & & 9.2 & & 9.2 & ND \\
\hline \multirow[t]{3}{*}{$B g / I^{c}+\underline{B a m H I}$} & $0.9 \mathrm{~B} 1,2$ & 0.9 & 0.9 & 0.9 & 0.9 & & ND \\
\hline & $1.0 \mathrm{~B} 1,2,3$ & & & 1.0 & & & ND \\
\hline & $3.0 \mathrm{~B} 1,2,3, \mathrm{Bm} 2$ & & & 3.0 & & 3.0 & ND \\
\hline Eco0109 & $3.4 \mathrm{E} 2, \mathrm{Hd} 4$ & & & & & & ND \\
\hline \multirow{2}{*}{$+\underline{\text { HindIII }}^{\mathrm{b}}$} & $6.2 \mathrm{E} 2,3, \mathrm{Hd} 4$ & & & & & & ND \\
\hline & $8.0 \mathrm{Hd} 2 / 3, E 2, \underline{3}, \mathrm{Hd} 4$ & 8.0 & 8.0 & 8.0 & 8.0 & 8.0 & ND \\
\hline \multirow[t]{2}{*}{$E c 00109+\underline{\text { BamHI }}$} & 1.4 Bml,E1 & 1.4 & 1.4 & $1.4^{\mathrm{f}}$ & 1.4 & $1.4^{f}$ & 1.4 \\
\hline & $3.8 \mathrm{Bm} 1, \mathrm{E} 1, \mathrm{Bm} 2$ & & & 3.8 & & 3.8 & 3.8 \\
\hline \multirow[t]{3}{*}{ Hae III ${ }^{\mathrm{c}, \mathrm{d}}$} & $0.5 \mathrm{H} 1, \mathrm{H} 2$ & 0.5 & 0.5 & 0.5 & 0.5 & 0.5 & ND \\
\hline & $0.2 \mathrm{H} 2, \mathrm{H} 3$ & 0.2 & 0.2 & $0.2^{\mathrm{e}}$ & 0.2 & $0.2^{\mathrm{e}}$ & ND \\
\hline & $0.6 \mathrm{H} 2, \underline{\mathrm{H} 3}, \mathrm{H} 4$ & & & $0.6^{\mathrm{e}}$ & & $0.6^{\mathrm{e}}$ & $\mathrm{ND}$ \\
\hline
\end{tabular}

Genomic DNA was isolated from plants with different forms of the Spm element, digested with the enzymes listed in the first column, fractionated on agarose gels, transferred to nylon membranes, and hybridized with a ${ }^{32} \mathrm{P}$-labeled cloned fragment of the $a$-gene sequence immediately adjacent to the Spm insertion site. The $a$-gene probe extends from the left end of the element to the $B g I I$ site in the $a$ gene (see Fig. 6), unless otherwise indicated. Restriction enzymes that are insensitive to methylation are underlined. All of the other enzymes are sensitive to methylation at C residues and contain either a CG dinucleotide or a CNG trinucleotide, except HaeIII (see footnote d). (ND) Not determined.

a Fragment lengths to which the $a$-gene probe will hybridize if the underlined sites shown next to the fragment size are not cleaved and all $a$-gene sites are cleaved. The location of each restriction site is shown in Fig. 6 . The length of each fragment detected by the $a$-gene probe therefore depends on whether or not a particular restriction site is methylated. The remaining columns list the sizes of 
ment's end. The GC-rich sequence corresponds to most of the first, untranslated exon of the element's major transcript. It has a $\mathrm{G}+\mathrm{C}$ content of almost $80 \%$ and contains $>70$ methylatable $\mathrm{C}$ residues (Pereira et al. 1986; Masson et al. 1987). The GC-rich region also contains 11 directly repeated copies of a sequence with strong homology to the 17-bp consensus sequence CGGGCGGGCGGCCTCGC.

There are striking differences among the active, cryptic, and programmable forms of the Spm element in the methylation of the GC-rich region. The SalI and the AvaI sites within the GC-rich region are almost fully methylated in cryptic elements and almost unmethylated in active ones (Fig. 4B,C). Identical results are obtained with stably active Spm elements (Table 2) and programmable Spm elements in the active phase (Fig. $4 \mathrm{~B}, \mathrm{C})$. Programmable elements in the inactive phase give a mixture of the fragments expected if the Sall and Aval sites within the GC-rich region are and are not methylated. The SalI site outside of the GC-rich region and near the element's internal BamHI site is methylated in all forms of the element. Comparable results have been obtained with BgII, for which there are two cleavage sites within the GC-rich region of the element (Table 2). The different forms of the element are therefore distinguishable in genomic DNA by their sensitivity to cleavage with methylation-sensitive restriction enzymes within the GC-rich region of the element.

Active and inactive elements can also be distinguished based on their sensitivity to two methylationsensitive enzymes, Eco0109 and HaeIII, which cleave at sites in the $0.2-\mathrm{kb}$ sequence upstream of the element's transcription start site (Fig. 1). The design and outcome of an experiment using Eco0109 are shown in Figure 5. The cryptic and the programmable elements in the inactive phase are indistinguishable and largely resistant to digestion with Eco0109, whereas the active element is almost fully cleaved. Similar results have been obtained using HaeIII, which cleaves a site within the Spm element $50 \mathrm{bp}$ from its $5^{\prime}$ end, except that the HaeIII site is methylated less extensively in inactive programmable and cryptic elements (Table 2). The element's activity phase is therefore correlated with the extent of methylation of upstream sequences, irrespective of the genetic stability of the phase setting. The results of all of the experiments on element methylation appearing in Table 2 are represented in the diagram shown in Figure 6.

Inactive programmable elements can be methylated
partially at more than one site

An experiment was done to determine whether the genomic DNA isolated from a plant with a programmable element in an inactive form comprises a mixture of completely methylated and unmethylated element copies or whether each element copy is methylated at a subset of sensitive $C$ residues. Genomic DNA digested with both BamHI and AvaI was fractionated on a gel, and both the AvaI-resistant 3.8 -kb fragment and the AvaI-digested 1.3-kb fragments containing the $5^{\prime}$ end of the element and the adjacent $a$-gene sequence were recovered and digested with Sall, as diagramed in the lower part of Figure 4A. Both fragment populations proved to contain a mixture of sensitive and resistant Sall sites (Fig. 4D). Hence, there are elements in the plant that are methylated at some sites but not at others, although there may also be elements that are methylated either at all possible sites or none of them.

\section{The Spm element's genetic activity is correlated with transcript levels}

To determine whether the genetic activity phase of an element is correlated with element transcription, poly $(\mathrm{A})^{+}$RNAs from plants with active and inactive elements were analyzed for the presence of transcripts homologous to the Spm element. We reported previously that a $2.5-\mathrm{kb}$ transcript was unique to plant tissues with an active Spm element (Pereira et al. 1986; Masson et al. 1987). This corresponds to the major transcript whose structure is shown in Figure 1. Consistently, we observe three to four transcripts that are smaller than the element's major transcript but are not unique to plants containing an active Spm element (Fig. 7). These may represent read-through transcripts from external promoters into defective elements or defective element transcripts initiated from the Spm promoter. Although they are not visible in the relatively brief autoradiographic exposure shown in Figure 7, there are also small amounts of two large transcripts of $\sim 6 \mathrm{~kb}$ that are

\section{(Continued from p. 1369.)}

the fragments detected by hybridization to the a-gene probe in digests of DNA isolated from plants in which the Spm element had been identified genetically as being in the form indicated at the top of the column.

b An $a$-gene probe extending $\sim 900 \mathrm{bp}$ from the $3^{\prime}$ end of the Spm element was used for this analysis.

c Methylation of BglI and HaeIII sites could not be determined by analysis of total genomic DNA due to the presence of comigrating fragments that hybridize to the $a$-gene probe. The comigrating fragments originate from the $a$ allele on the homolog and other genomic sequences homologous to the $a$ locus. To analyze these sites, 3.8 -kb fragments were first gel purified from BamHI-digested genomic DNA samples, digested with BglI or HaeIII, refractionated, then hybridized to an a-gene probe. Rehybridization of the same filters with an internal Spm probe gave results consistent with those obtained using the a-gene probe (not shown).

d The HaeIII restriction enzyme will not cleave its recognition sequence ( 5 'GGCC) if the internal $\mathrm{C}$ residue of the sequence is methylated. Because CNG trinucleotide sequences are commonly methylated in plants, the HaeIII recognition site can be methylated if followed by a G residue. There is a $\mathrm{G}$ residue adjacent to the $\mathrm{H1}, 2$, and 3 sites, but not the $\mathrm{H} 4$ site. The $\mathrm{H} 4$ site is therefore methylation insensitive, whereas the $\mathrm{H} 1, \mathrm{H} 2$, and $\mathrm{H} 3$ sites are potential methylation sites.

e The 0.2 - and 0.6 -kb fragments hybridize to the $a$-gene probe with equal intensity.

f This fragment hybridizes faintly to the a-gene probe, compared to other fragments. 
A)
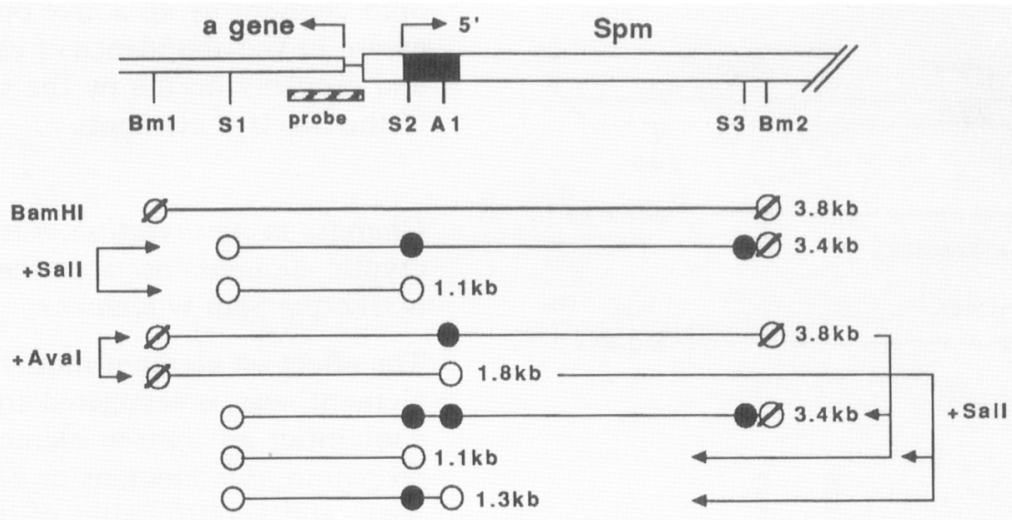

B)

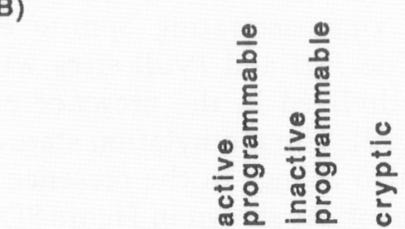

C)

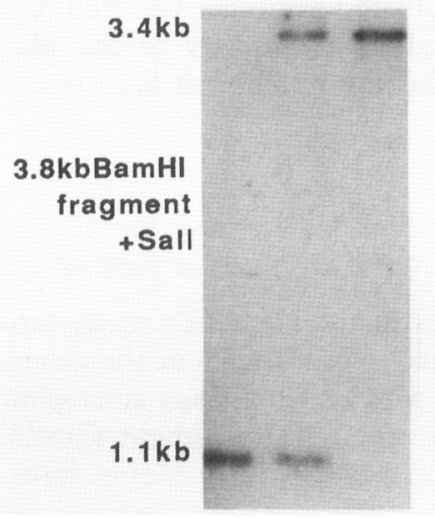

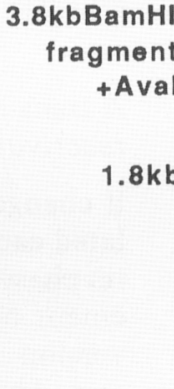
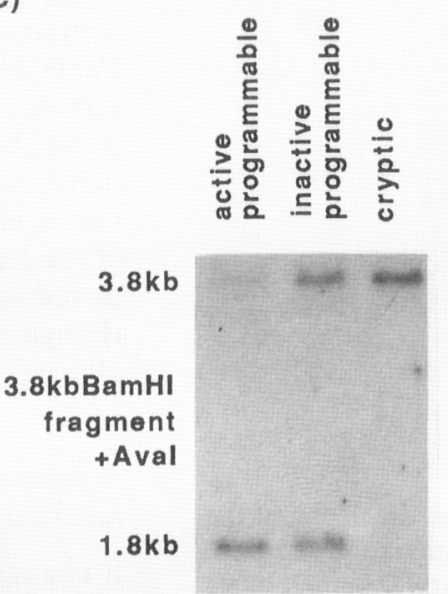

D)
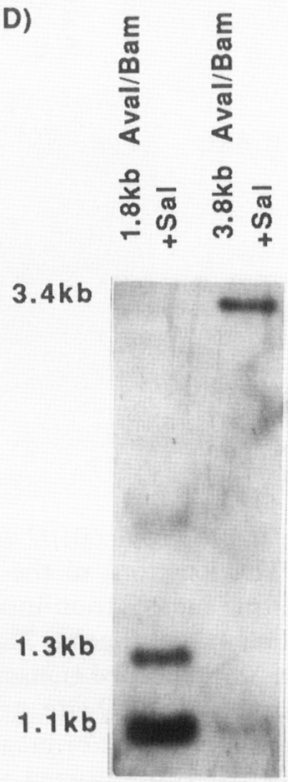

Figure 4. Methylation of the SalI and Aval sites within the 5' GC-rich region of $\operatorname{Spm}$. $(A)$ The location of the methylation-sensitive Sall and $A v a I$ sites and the methylation-insensitive BamHI sites within the Spm element and $a$ gene. The solid box represents the first exon of the major Spm-encoded transcript. To determine the methylation state of the AvaI and Sall sites, 3.8-kb fragments were gel purified from BamHI-digested genomic DNAs, then digested with either AvaI or Sall, and hybridized with the a-gene probe shown. Digestion with Sall or AvaI can give a number of fragments detectable by the a-gene probe, depending on whether or not the sites are methylated. (A) The possible fragments and their sizes, assuming complete cleavage of the a-gene sites, are shown. To determine the methylation state of the SalI site in fragments either digested or undigested by AvaI, DNA isolated from a plant with an inactive programmable element was digested with both $A v a \mathrm{I}$ and BamHI. DNA fragments in the 3.8-kb size range (uncleaved at the $A v a \mathrm{I}$ site) and 1.8-kb size range (cleaved at the AvaI site) were gel purified, digested with Sall, and hybridized to the a-gene probe. The sizes of the fragments detectable by the $a$-gene probe (bottom) will depend on whether or not the Sall sites are cleaved. $(B, C)$ The results of $a$-gene probe hybridization to the SalI-digested $(B)$ and AvaI-digested $(C) 3.8-\mathrm{kb} B a m H I$ fragments. $(D)$ Results of $a$-gene probe hybridization to the gel purified and Sall-digested 1.3- and 3.8-kb AvaI-BamHI fragments. () Uncleaved, methylation-sensitive restriction site; $(O)$ cleaved, methylation-sensitive restriction site; (Ø) cleaved, methylation-insensitive restriction site. (A) $A v a I ;(B m) B a m H I ;(S)$ SalI.

unique to Spm-containing plants. One of these has also been noted in En-containing plants (Pereira et al. 1986), and they may be splicing intermediates or alternatively spliced mRNAs.

Plants with active and inactive Spm elements differ in the abundance of the major $2.5-\mathrm{kb}$ element-encoded transcript (Fig. 7). The transcript is relatively abundant in plants containing either a stably active or active programmable Spm element, although there is considerable variation between plants in the abundance of the transcripts (Fig. 7, lanes 1 and 2). The 2.5-kb Spm transcript is not detectable in plants containing either an inactive programmable or a cryptic element. The genetic observation that an inactive programmable element can be 
A)

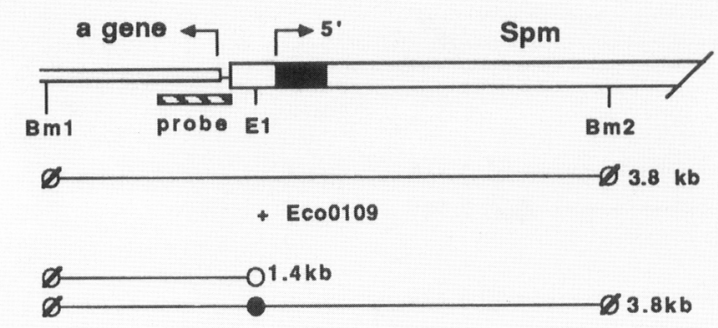

B)

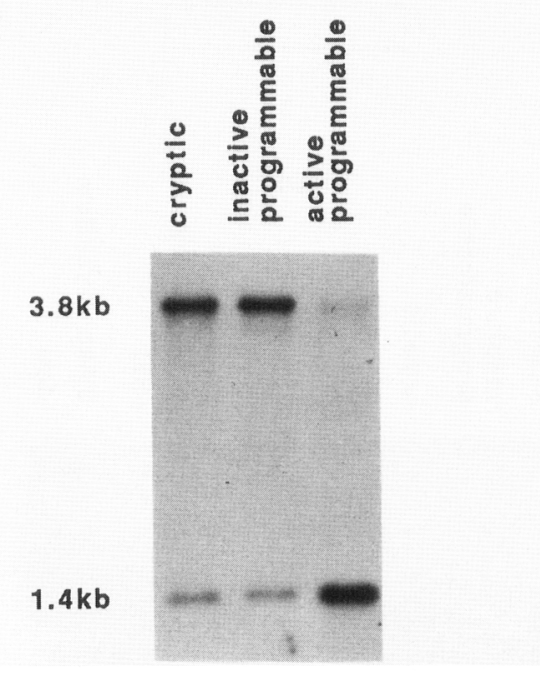

Figure 5. Methylation of the Eco0109 site at the $5^{\prime}$ end of the Spm element. $(A)$ The locations of the methylation-sensitive Eco0109 site and the methylation-insensitive BamHI sites within the Spm element and $a$ gene. The solid box represents the first exon of the Spm-encoded transcript. To determine the methylation state of the Eco0109 site, genomic DNAs isolated from plants having either cryptic or programmable lactive and inactive) Spm elements were digested with BamHI and fractionated on agarose gels. $(A)$ DNA fragments in the $3.8-\mathrm{kb}$ size range were gel purified, digested with Eco0109, and then hybridized to the $a$-gene probe. (Bottom) The probe will hybridize to a 1.4-kb fragment if the Eco0109 site is cleaved and to a 3.8$\mathrm{kb}$ fragment if the site is not cleaved. $(B)$ The results of a blot hybridization experiment described in $A$. (O) Uncleaved, methylation-sensitive restriction site; (O) cleaved, methylation-sensitive restriction site; $(\varnothing)$ cleaved, methylation-insensitive restriction site. (Bm) BamHI; (E) Eco0109.

reactivated by an active element (McClintock 1957, $1958,1959,1971$; Fedoroff and Banks 1988) was investigated by examining the effect of a trans-acting $S p m-w$ element on the abundance of element-encoded transcripts in the presence of either an inactive programmable element or a cryptic element. The results show that element-homologous transcripts are markedly more abundant in plants containing both an Spm-W and an inactive programmable element than in plants containing the Spm-W and a cryptic element or either an inactive programmable or an Spm-w element alone. We conclude that genetic reactivation of an inactive programmable
Spm element by an active one is correlated with an increase in the abundance of element-encoded transcripts and probably occurs by the transcriptional reactivation of the inactive element.

Changes in methylation of inactive programmable and cryptic elements occur in the presence of $a$ transactivating Spm-w element

The effect on element methylation of a trans-activating element was investigated in genomic DNA of plants containing an $S p m-W$ element and either an inactive programmable element or a cryptic element. The Sall, AvaI, and Eco0109 sites of inactive programmable elements are partially and variably methylated in the absence of a trans-activating Spm-w element (Fig. 8B,C; Table 2). These sites are not methylated when the plant contains a trans-activating Spm-w element (Fig. 8B; Table 2). The PstI and PvuIl sites within the element remain methylated in the presence of the $S p m-W$ element (Table 2). The methylation state of the cryptic element can also change in the presence of the trans-activating element. As shown in Figure $8 \mathrm{D}$, the methylation of the Sall site within the GC-rich region of the element is reduced in a majority of the plants examined, although the site remains at least partially methylated in all cases.

A trans-activating element promotes the heritable reactivation of an inactive programmable element

If changes in the element's methylation pattern are related causally to changes in the genetic transmission of its phase setting, then trans-activation of an inactive element by the Spm- $W$ element should promote its conversion to a heritability active form. This was determined by comparing the transmission of an inactive programmable element from each of several parental plants, through an intermediate generation in which it was or was not exposed to a trans-activating $S p m-w$, to the following generation.

Because sibling plants exhibit large variations in the heritability of programmable Spm element's state of activity, the ability of a trans-activating element to reprogram an inactive element was evaluated by comparing the inheritance of the element's state of activity through the male and female gametes produced on the main stalks of individual plants. We reported previously that an inactive programmable element has a higher probability of being transmitted in an inactive state through male than female gametes (Fedoroff and Banks 1988). Moreover, an active element in the programmable form has a higher probability of being inactivated upon transmission through male than female gametes. This tendency is evident when the fraction of progeny kernels on ears receiving an element from a plant through the female gametes is compared with the fraction of kernels that receives an inactive element through the male gametes produced on the main stalk of the same plant (Fig. 9 , left panel). 


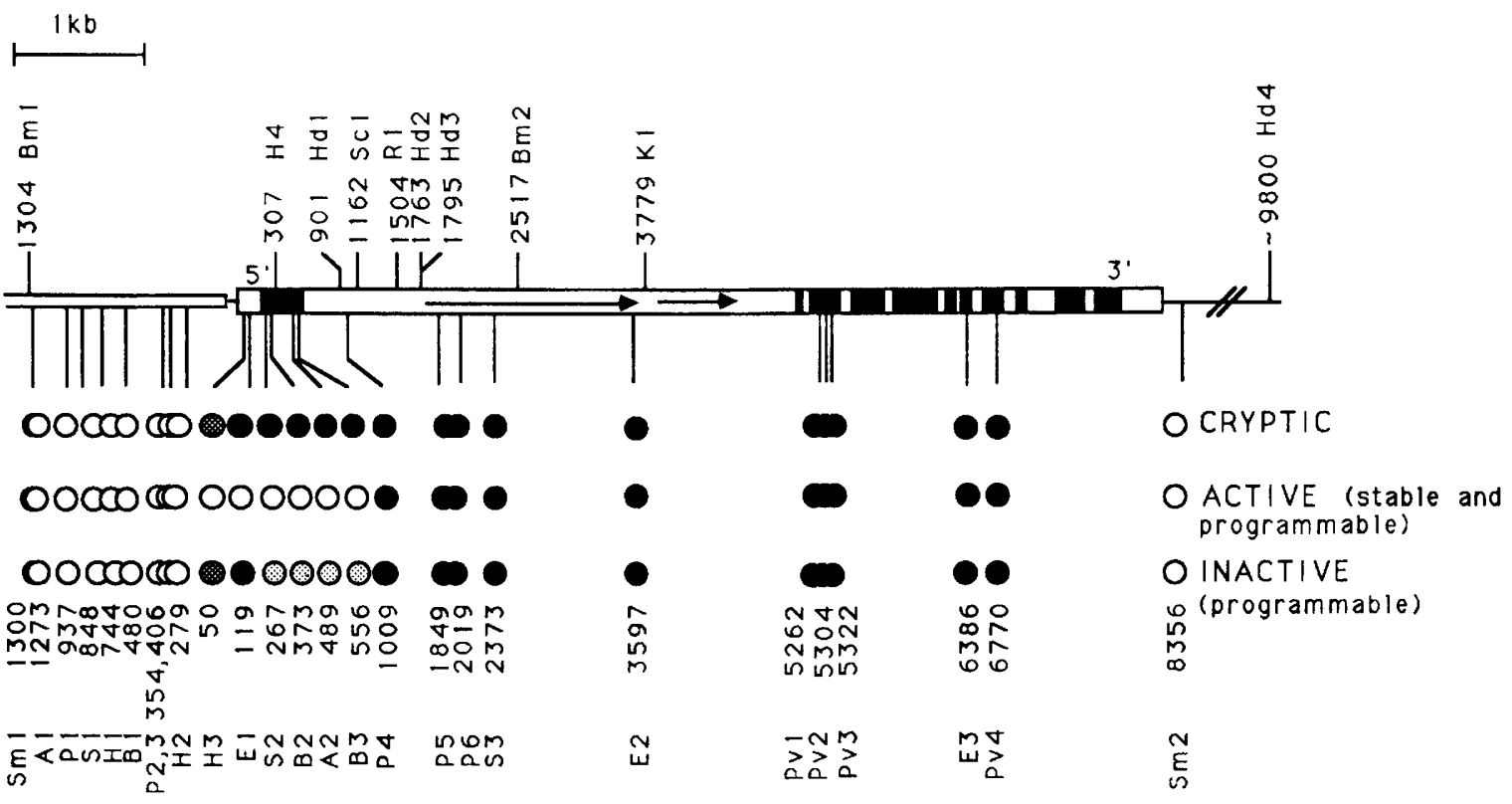

Figure 6. The location of methylated restriction enzyme sites in the Spm element and adjacent sequences. The solid boxes in the Spm element represent the exons of the major Spm-encoded transcript. The arrows correspond to the two open reading frames within the first intron of the transcription unit. Restriction sites for enzymes that are sensitive to methylation are shown below the element. Restriction sites for enzymes that are insensitive to methylation and used in these experiments (Table 2) are shown above the element. Each of the several restriction sites for a given enzyme has been numbered from left to right in the diagram. The number above each restriction site is the distance (bp) of that site from the $5^{\prime}$ end of the element. (A) AvaI; (B) BglI; (Bm) BamHI; (E) Eco0109; (H) HaeIII; (Hd) HindIII; (K) KpnI; (P) PstI; (Pv) PvuII; (R) EcoRI; (S) SalI; (Sc) ScaI; (Sm) SmaI. (Solid circle) Methylation-sensitive restriction site almost completely methylated; (shaded circle) methylation-sensitive restriction site partially methylated (the density of shading reflects the extent of methylation); (open circle) methylation-sensitive restriction site almost or completely unmethylated.

When the plant transmitting the inactive programmable element also contains a trans-activating Spm-w element, the element is more likely to be transmitted to the next generation in an active form than if the plant does not contain a trans-activating element. In the plant family for which data appear in Figure 9, the difference is most striking when the tendency of the element to be reactivated is compared between male and female gametes of the same plant (Fig. 9, right panel). The presence of a segregating, trans-activating Spm element reverses the tendency toward element inactivation in the male germ line. Although the structure of the crosses used in the present experiment precludes a rigorous evaluation of the effect of the trans-acting element within the family, a recently completed study has provided extensive documentation of the Spm-w element's ability to promote the heritable reactivation of inactive elements (Fedoroff 1989). Thus, a trans-activating Spm

Figure 7. Northern blot analysis of poly $(A)+$ RNA isolated from individual plants with various Spm elements. Approximately $5 \mu \mathrm{g}$ of poly(A) ${ }^{+}$RNA isolated from whole plant tissue was fractionated on a formaldehyde-agarose gel, transferred to membrane filters, and hybridized with a ${ }^{32}$ p-labeled Spm cDNA fragment (see Methods).

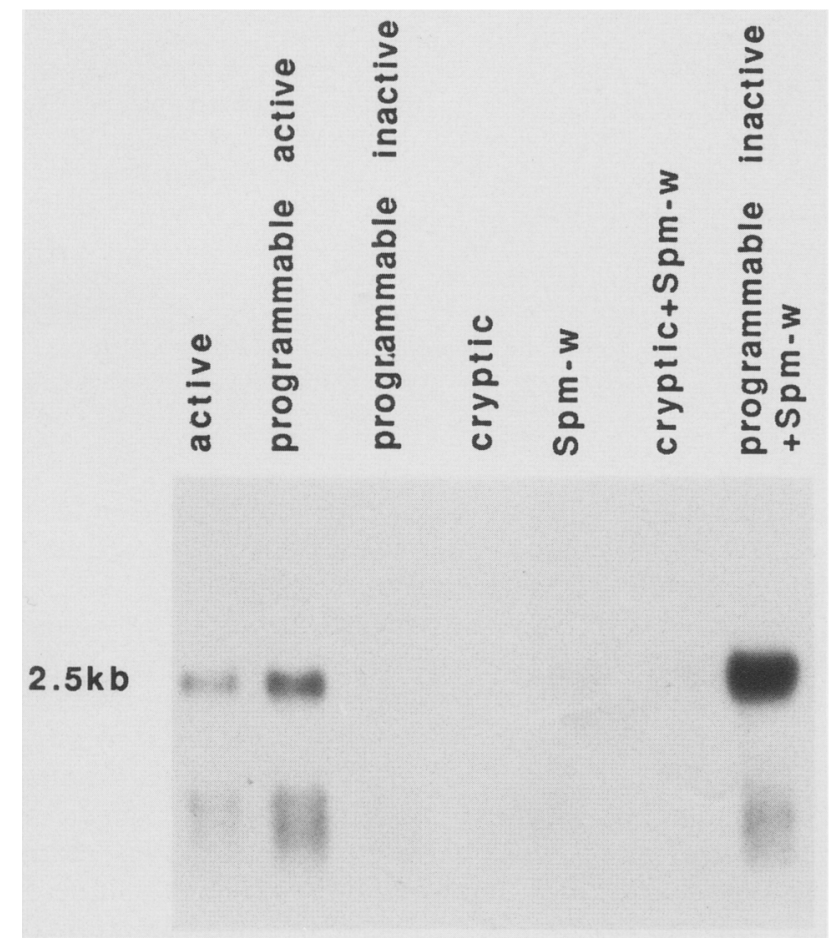


Banks et al.
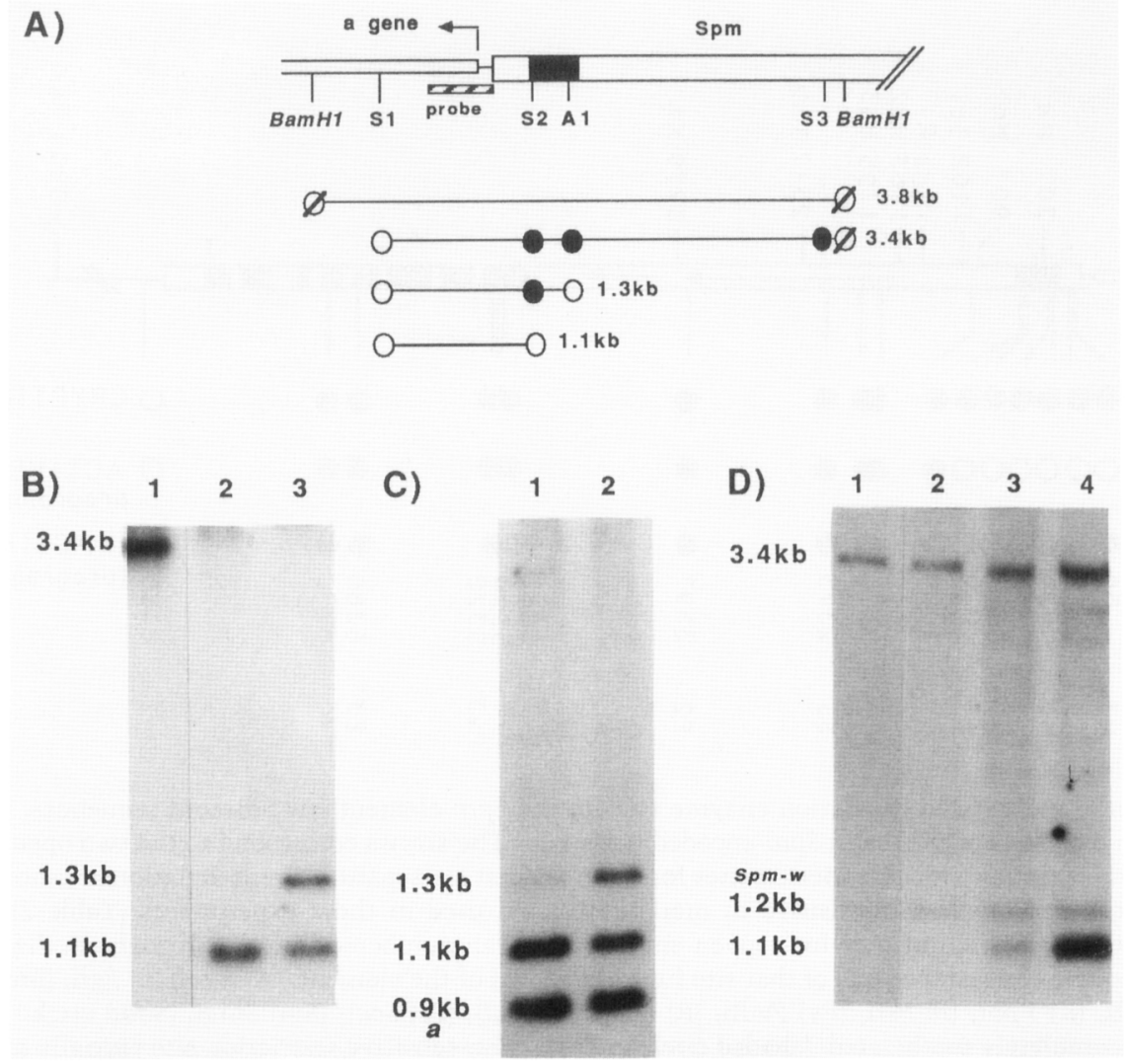

Figure 8. Methylation of sites at the $5^{\prime}$ end of inactive programmable Spm elements and cryptic elements in the presence and absence of an Spm-w element. (A) The location of the methylation-sensitive SalI and AvaI sites and the methylation-insensitive BamHI sites in the Spm element and adjacent $a$-gene sequences. The solid box represents the first exon of the Spm-encoded transcript. The lines below the diagram represent the fragments detectable by hybridization to the $a$-gene probe after digestion of DNA with different combinations of BamHI, SalI, and AvaI. $(B)$ To show the effect of an Spm-w element on the methylation of an inactive programmable element, fragments in the 3.8 -kb size range were gel purified from BamHI-digested genomic DNAs, digested with $A v a I$ and Sall, refractionated, and hybridized with the $a$-gene probe shown in $A$. Results of blot hybridization to DNA isolated from plants with a cryptic element but no Spm-w element (lane 1), both an inactive programmable and an Spm- $w$ element (lane 2), and an inactive programmable element but no Spm-w element (lane 3). $(C)$ Variation in the extent of methylation of sites at the $5^{\prime}$ end of the Spm element among plants with an inactive programmable element. Genomic DNA was isolated from two sibling plants (lanes 1 and 2) with an inactive programmable element, digested with $A v a$ I and Sall, and hybridized with the $a$-gene probe shown in $A$. The ratio of 1.3- to 1.1-kb fragments corresponds to the proportion of DNA molecules that are not cleaved to those that are cleaved by Sall in the population of DNA molecules that are cleaved at the $A v a$ I site. The $0.9-\mathrm{kb}$ fragment in each lane corresponds to the $a$ allele present on the homolog in both plants. $(D)$ The effect of an Spm-w element on the methylation of a cryptic Spm element. Genomic DNA was isolated from plants with only a cryptic element (lane 1) or both a cryptic Spm and an Spm-w element (lanes 2-4), digested with $B a m H I$ and SalI, and hybridized with the $a$-gene probe shown in $A$. The 1.2-kb fragment corresponds to the $a-m 5-S p m-w$ allele present on the homolog in all plants. The additional fragments that hybridize weakly to the probe correspond to other genomic sequences with homology to the $a$ gene and are observed in control plant DNAs as well. (O) Uncleaved, methylation-sensitive restriction site; (O) cleaved, methylation-sensitive restriction site; (Ø) cleaved, methylation-insensitive site. (A) AvaI; (Bm) BamHI; (S) SalI.

element not only promotes the transient activation of an inactive element but which also promotes its heritable reactivation (Fig. 9; Fedoroff 1989).

Similar genetic experiments have also been done with the $a-m 2-8167 B$ (cryptic) element, which shows variably reduced methylation of sites within the GC-rich region (Fig. 8d). The cryptic element almost always segregates from the trans-activating Spm- $w$ element in its original form. However, very rare instances of genetic reactivation have been observed in the presence of a trans-acting element (N. Fedoroff, unpubl.) and were the source of the $a-m 2-8167 B$ (reactivated) allele shown in Figure $2 \mathrm{~b}$ (for details, see Methods). It appears, therefore, that there is a correlation between the extent to which element methylation is reduced by a trans-activating element and the probability that it will be heritably reactivated. Although the precise magnitude of the increase in the frequency of reactivation attributable to the transactivating Spm- $W$ element has not been determined for the $a-m 2-8167 B$ allele, it has been for other cryptic Spm elements and is between 2 and 3 orders of magnitude ( $N$. Fedoroff, in prep.). Thus, the trans-acting element can both reset the element's phase of activity and heritably reprogram the element. 


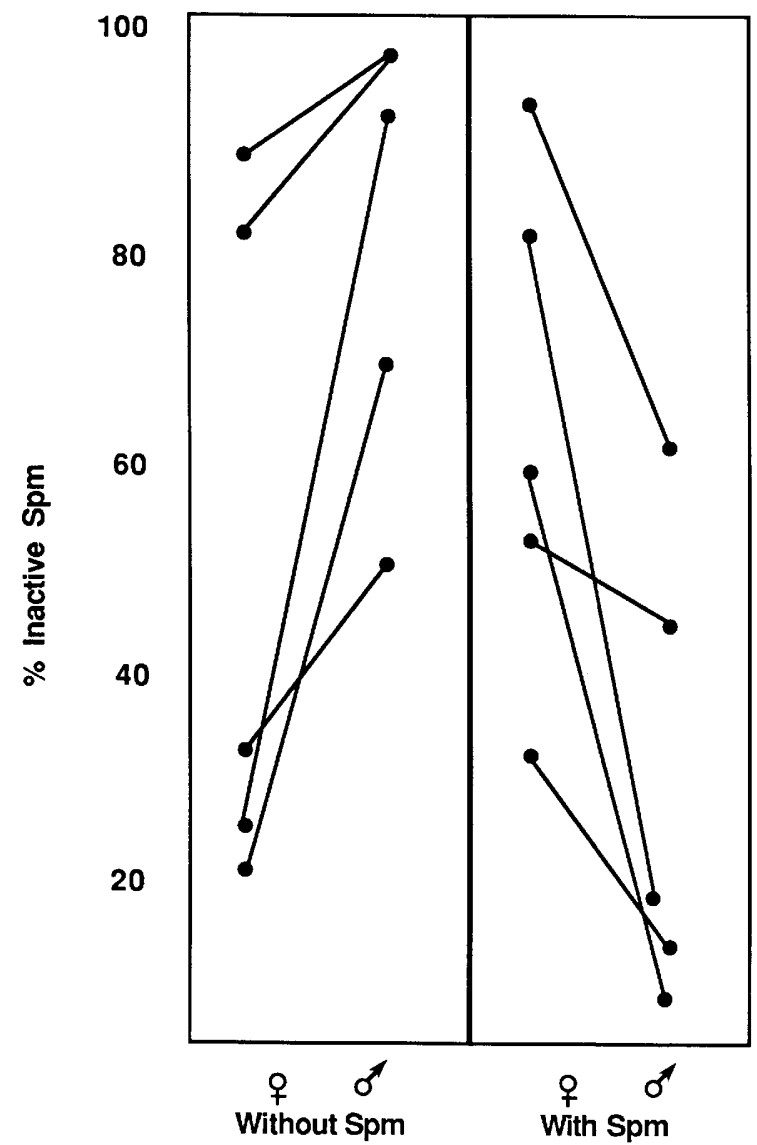

Figure 9. Heritable reactivation of an inactive programmable Spm following exposure to a trans-activating Spm-w element. In the previous generation, plants carrying an inactive programmable Spm element [ $a-m 2-7991 A 1$ (Spm-i) allele] were used as pollen parents in crosses to plants that were homozygous either for the $a$ or the $a-m 5-S p m-w$ alleles. Kernels that were heterozygous for the Spm insertion allele and either the $a$ or $a-m 5$ $S p m-w$ allele were selected, grown, and the first ear on the main stalk was backcrossed to a tester strain that was homozygous for the $a$ allele. All of the selected kernels had the variegated phenotype expected if the Spm element at the $a$ locus is active. The tassel on the main stalk of each plant was used as the pollen parent in the same type of backcross. Progeny ears were examined to determine the fraction of kernels with an inactive Spm. The frequency with which the Spm element is transmitted in an inactive form through the male and female gametes is compared for one family of plants that received the Spm element from the same original plant through a plant in the following generation that had no active Spm (left) or was homozygous for the $a-m 5-S p m-w$ allele (right). Each pair of dots connected by a line represents the percentage of progeny kernels that received an inactive Spm element through the female and male gametes, respectively, produced on the main stalk of a single plant.

\section{Discussion}

Control of Spm expression is exerted at the level of element transcription

We have presented evidence that a genetically inactive Spm element is transcriptionally silent, whereas an ac- tive element is transcribed, suggesting that the phase setting mechanism controls element activity at the transcriptional level. Regardless of whether the element is in the stable or programmable form, active elements are hypomethylated at sites upstream of the element's transcription start site, whereas inactive elements are almost completely methylated. The extent of methylation at the element's upstream Eco0109 and HaeIII sites is the same in a cryptic element and in an inactive element in the programmable form, suggesting that the methylation level of sites in the element sequence upstream of its transcription start site determines its phase of activity.

\section{Molecular differences between cryptic and} programmable elements in the inactive phase

A cryptic element differs from a programmable element in the inactive phase by the developmental and hereditary stability of the inactive phase setting (Table 1). Programmable elements can display different patterns of phase reversal during development (McClintock 1957, 1962, 1965a; Peterson 1966; Fowler and Peterson 1978; Fedoroff and Banks 1988). Such patterns are heritable but relatively unstable and subject to frequent further changes. In the present experiments, we have found that cryptic and programmable elements differ in the methylation pattern of several sites within a GC-rich region of the element located just downstream of its transcription start site. A cryptic element is fully methylated at all of the sites that we have examined, whereas the inactive programmable elements in a given plant are partially methylated at each site, implying that a given element is methylated at a subset of sites. Moreover, different plants in a population of sibling plants grown from kernels of the same phenotype vary in the extent of methylation at a given site. Reactivation of an inactive element is accompanied by a reduction in the level of methylation of sites within the GC-rich region of the element but not elsewhere in the element.

An Spm element-encoded gene product promotes both the transient and heritable activation of an inactive element

Cryptic and programmable elements differ in their response to the presence of a trans-activating element. A cryptic element is not transcriptionally activated in the presence of a trans-acting Spm element. In contrast, an inactive element in the programmable form is fully active genetically, as well as transcriptionally, in the presence of a trans-activating element. The first implication of these observations is that an element-encoded gene product can override the genetic mechanism that sets the element's phase, effecting its transcriptional activation. Their second implication is that the ability of the element-encoded gene product to override the phase-setting mechanism depends on the stability of the element's inactive state, which we have ascribed to the mechanism that is responsible for programming the element. Although the elements we have compared in the 
trans-activation tests reported here exhibit extreme differences in the stability of the inactive state, genetic tests conducted on plants with elements in the program. mable form reveal these to be endpoints in a continuum. That is, plants in which the resident element has been reprogrammed to increase the heritability of the inactive state exhibit a concomitant decrease in the ability of an incoming trans-activating element to reactivate the resident, inactive element (N. Fedoroff, unpubl.).

Examination of the methylation pattern of inactive elements in plants containing a trans-activating Spm revealed a marked reduction in methylation of the GCrich region, as well as of the upstream Eco0109 and HaeIII sites. The results of genetic tests showed that exposure to a trans-activating element also promotes the heritable conversion of a genetically inactive element to an active one. Moreover, there is a good correlation between the initial extent of methylation, the reduction in methylation during trans-activation, and the heritable reversal of the inactive state. These observations imply that the Spm element encodes a gene product that not only activates element transcription but also promotes the heritable reprogramming of an inactive element by reducing its level of methylation.
A simple molecular model for the developmental regulation of the Spm element

A rather simple molecular mechanism can explain the full range of the observed modes of Spm expression in development (Fig. 10). Based on the present results, we propose that the element's phase setting is determined by the methylation state of sequences on the $5^{\prime}$ side of its transcription start site (upstream control region, or UCR), whereas its developmental program is determined by the methylation pattern within the GC-rich sequence of its first exon (downstream control region, or DCR). We postulate that the element's promoter is constitutively active when both UCR and DCR are hypomethylated but that its expression becomes dependent on the presence of the element's positive autoregulatory gene product (circled A in Fig. 10) when the UCR is methylated and the DCR is partially methylated. We postulate further that whether and to what extent the element's positive autoregulatory gene product can activate element expression depends on the methylation state of the GC-rich DCR (Fig. 10). When both UCR and DCR are fully methylated, the element's promoter is inactive and uninducible.
A)

Active Spm
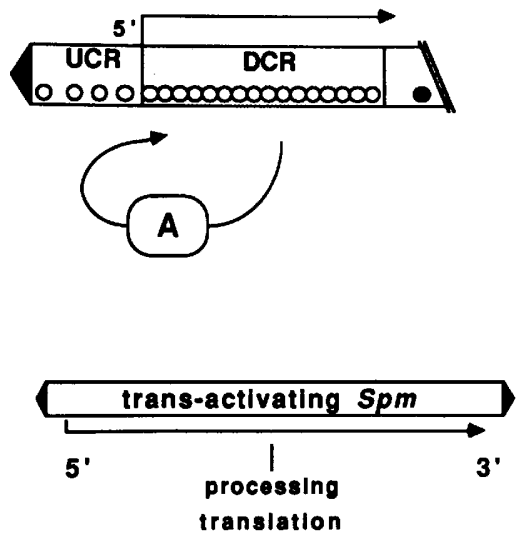

B) Programmable Spm
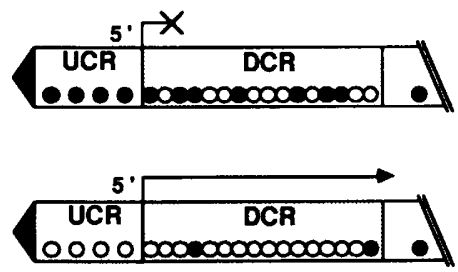

C) Cryptic Spm
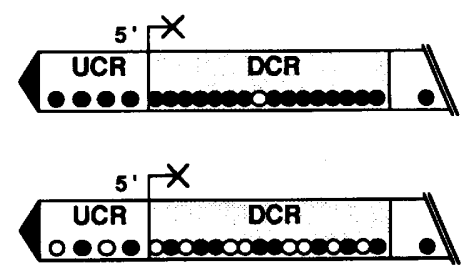

A

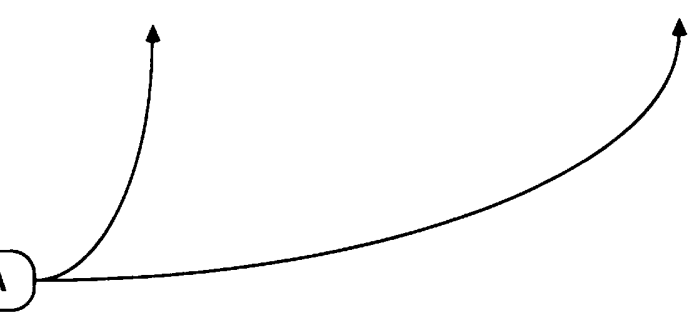

Figure 10. A molecular model of Spm regulation. The diagrams represent the Spm element's $5^{\prime}$ end. The transcription start site at nucleotide 209 (Pereira et al. 1986) is indicated by the base of the arrow above the diagram of each element. Extended and truncated arrows designate transcriptionally active and inactive elements, respectively. The $0.2-\mathrm{kb}$ UCR contains 11 methylatable $\mathrm{C}$ residues; these are represented by four circles. The DCR commences at the transcription start site and includes the 0.35-kb GC-rich sequence within the element's first exon. There are 75 methylatable C residues in the DCR, and these are represented by 16 circles in the DCR. Open circles represent unmethylated sites, whereas shaded and solid circles represent partially and fully methylated sites. The circled A represents the postulated Spm-encoded positive autoregulatory gene product (Masson et al. 1987). (A) The stably active Spm element is represented as unmethylated. The looped arrow indicates that the active element remains in an active form as a consequence of producing the circled $A$, the postulated autoregulatory gene product that functions as a transcriptional activator and interferes with methylation of the UCR and DCR. $(B)$ The programmable Spm (top) is depicted as methylated within the UCR, partially methylated in the DCR, and transcriptionally silent. (Bottom) The transcriptionally activated, hypomethylated form of the programmable element observed in the presence of a trans-activating Spm, which provides the element with the circled A, thereby promoting its transcriptional activation and decreasing its level of methylation. (C) The cryptic element $($ top $)$ is represented as almost fully methylated and transcriptionally inactive. (Bottom) The reduced methylation of the cryptic element observed in the presence of the circled A provided by the trans-activating Spm element at the left. The density of methylation in the presence of the circled A is depicted as sufficiently high to prevent its transcriptional activation. 
We suggest that when the element is in the stably active form, its autoregulatory gene product serves to maintain it continuously in a transcriptionally active form, both by overriding the inhibitory effect of methylation and by continuously promoting the heritable 'erasure' of methylation, possibly by binding directly to UCR and DCR sequences to activate transcription and interfere with remethylation during DNA replication (Fig. 10). In contrast, an element in the extremely cryptic state is genetically and transcriptionally silent because both its UCR and DCR are fully methylated. Although its methylation level decreases in the presence of a trans-activating element, the reduction is partial. Such an element can neither be expressed constitutively nor trans-activated by the positive autoregulatory gene product supplied by an active element in the same genome. Finally, we postulate that a programmable element is in one of many possible intermediate states of methylation, within each of which the density and, perhaps, the pattern of methylation of the GC-rich DCR determines when, where, and how frequently in development the element will undergo a change in its phase setting, mediated by a change in the methylation state of the UCR. As discussed below, developmental differences in the plant's ability to methylate the UCR and DCR comprise the final component of the $S p m$ 's regulatory scheme.

There are indications that the DCR also plays a role in determining the timing and frequency of element transposition, in addition to participating in the regulation of element transcription. We have reported that a mutant element from which the DCR sequence is deleted, but which retains both the element's terminal inverted repeats and the subterminal repetitive regions adjacent to them, excises very infrequently in the presence of a trans-activating Spm element (Masson et al. 1987). The excisability of the highly methylated element of the $a-m 2-8167 B$ (cryptic) allele is also low (Fig. 2f) and comparable to that of a defective element lacking the DCR (Masson et al. 1987). When the resident Spm element is reactivated fully, it shows a high frequency of somatic excision (Fig. 2b). Moreover, we have recovered derivatives of the $a-m 2-8167 B$ (cryptic) allele that exhibit a high frequency of excision in the presence of a trans-activating element (N. Fedoroff and J. Banks, unpubl.). These observations not only suggest that the interaction between the Spm's autoregulatory protein and the DCR is involved in element transposition but also that the methylation state of sequences within the element and the plant's ability to remethylate are important determinants of transposition frequency.

It is not yet clear whether the element's autoregulatory gene product and the element-encoded transposition function reside in the same or different gene products (Pereira et al. 1986; Masson et al. 1987). There is a single major $2.5-\mathrm{kb}$ transcript unique to Spm-containing plants (Pereira et al. 1986, Masson et al. 1987), as well as two minor larger transcripts (Pereira et al. 1986; J. Banks and N. Fedoroff, unpubl.). Data obtained from the molecular analysis of the structure of mutant Spm elements are consistent with the interpretation that both genetic activities of the element are encoded by the element's major transcript but do not eliminate the possibility that one of the activities resides in a protein encoded by a minor transcript obtained by an alternative splicing pattern from the element-encoded primary transcript (Pereira et al. 1986; Masson et al. 1987). Our recent demonstration that the Spm element transposes in transformed tobacco cells will facilitate the resolution of these questions (Masson et al. 1988).

\section{Methylation is also correlated with the inactivation of other maize transposable elements}

Although the inactivation and reactivation of the maize Activator $(A c)$ element have been studied in less detail than that of the Spm element, the $A c$ element provided the first genetic, as well as the first molecular, evidence that an epigenetic mechanism associated with element sequence methylation was responsible for its inactivation (McClintock 1965a,b; Fedoroff et al. 1983; Schwartz and Dennis 1986; Chomet et al. 1987; Schwartz 1988). Changes in the methylation pattern of sequences around the transcription start site accompany changes in the genetic activity of the $A c$ element as they do in the Spm element. However, partially methylated $A C$ elements appear to retain their genetic activity (Schwartz and Dennis 1986). A correlation has also been reported between the extent of methylation and the mobility of $\mathrm{Mu}$ element sequences in maize (Bennetzen 1985; Chandler and Walbot 1986; Walbot 1988). However, in the case of the $M u$ elements, there is insufficient genetic information to permit a distinction to be made between effects on expression of a mobilizing element and on the mobility of a transposition-defective element.

\section{The Spm element may be under the control of a basic plant developmental regulatory mechanism}

The ability of different parts of the maize plant to differentially reset and reprogram Spm elements in the programmable form appears to be universal. Both McClintock (1958) and Fowler and Peterson (1978) noted marked differences in element expression between ears borne on tillers and on the plant's main stalk. Our studies on programmable derivatives of two different Spm insertion alleles of the $a$ locus amply confirmed these early observations and further established the existence of differences between male and female germ lines in the capacity to maintain or impose an inactive phase setting (Fedoroff and Banks 1988).

The results of our genetic studies on the Spm element revealed a consistent relationship between the fate of the element's phase program and the position on the plant of the meristem that gives rise to the plant part or reproductive structure transmitting the element to the succeeding generation (Fedoroff and Banks 1988). The plant's ability to inactivate an active element increases with distance from the base of the plant of the meristem producing each reproductive structure: tiller, second ear, first ear, and tassel (Fedoroff and Banks 1988). Moreover, 
there is a parallel between the mode of operation of the $S p m$ element's developmental regulatory system and that which determines the developmental fate of a given meristem. The lowermost nodes can give rise to uncommitted lateral buds that produce fertile tillers. Those produced at successively higher nodes first undergo an incremental determination that commonly results in the production, both on field-grown plants and in culture-derived plants, of shoots with shortened internodes that terminate in an influorescence producing both male and female flowers (Raman et al. 1980). Higher nodes are fully determined to produce ears, which bear only female flowers. Finally, bud development above the earbearing nodes is suppressed completely. The observation that the developmental fate of a given meristem is determined early and maintained in culture suggests the involvement of a stable genetic change. Based on these evident parallels, we have formulated the hypothesis that the Spm element has come under the control of a mechanism that is involved in the plant's transition from the juvenile to adult phase and participates in determining the developmental fate of the apical and lateral meristems.

\section{Methods}

Maize strains and genetic methods

All of the experiments were done with two derivatives of the original a-m2 allele (McClintock 1962; Masson et al. 1987). These are the $a-m 2-7991 A 1$ and the $a-m 2-8167 B$ (cryptic) alleles. Both contain structurally identical, full-length Spm-s elements at precisely the same insertion site, and both Spm-s elements have been cloned (Masson et al. 1987). The element in the $a-m 2-7991 A 1$ allele has been completely sequenced, whereas the Spm-s element of the $a-m 2-8167 B$ (cryptic) allele has been extensively analyzed by restriction endonuclease mapping, and its termini have been sequenced (Masson et al. 1987). No differences were detected between the two elements, but a trinucleotide insertion was found adjacent to the $3^{\prime}$ terminus of the element in the $a-m 2-7991 A 1$ allele that was not present in either the $a-m 2-8167 B$ (cryptic) allele or any of the other $a-m 2$ derivatives for which insertion site sequences were determined (Masson et al. 1987).

The original $a-m 2-8167 B$ allele received from McClintock was phenotypically similar to other derivatives of the original $a-m 2$ allele in which the Spm element had sustained an internal deletion, rendering it transposition defective. That is, the element does not excise or transpose, except in the presence of a trans-acting Spm located elsewhere in the same genome. In our original molecular description of this allele, we raised the possibility that its insertion was not genetically defective but actually represented a cryptic element (Masson et al. 1987). Using genetic conditions that promote activation of cryptic and inactive elements (Fedoroff 1986; Fedoroff and Banks 1988), we recently recovered a derivative of the original $a-m 2-8167 B$ allele with a reactivated Spm-s element that exhibits the phenotype of the original $a-m 2$ allele, itself no longer in existence. This was done by selecting and growing kernels exhibiting a high frequency of somatic reversion, either in sectors or throughout the aleurone layer, on ears produced by plants containing a trans-acting second Spm element. We have reclassified the $a-m 2-8167 B$ allele as having an insertion of a cryptic, and not a genetically defective, Spm element, redesignating it the $a-m 2-8167 B$ (cryptic) allele. The derivative with a reactivated element is designated $a-m 2-8167 B$ (reactivated).

The second allele used in the present studies, the $a-m 2-7991 A 1$ allele, was selected as a starting point for the isolation of a derivative with an element capable of undergoing the types of programmed changes in activity that had been described previously for Spm elements at other (and unidentified) chromosomal locations (McClintock 1957; Masson et al. 1987). Our purpose was to isolate such a derivative at a locus for which cloned probes were available to simplify the analysis of the element in genomic DNA, a task that is complicated by the abundance of genomic sequences with homology to the Spm element. The derivation and genetic analysis of such alleles, here termed programmable, has recently been described (Fedoroff and Banks 1988).

Genetic methods for the analysis of the $a-m 2$ derivatives are those previously described (Fedoroff and Banks 1988). In all cases except that of the cryptic element, the chromosome carrying the $a-m 2$ derivative with an Spm element in either the active or inactive form was maintained on a chromosome in which it was closely linked to the Sh2 allele of the sh2 locus and which was heterozygous with a chromosome carrying either stable null alleles of both loci $(a, s h 2)$ or the sh2 allele and an allele of the $a$ locus containing a $d S p m$ element $(a-m 1$ $5719 A 1)$. Table 1 gives the percentage of progeny kernels with an inactive element on ears, either of plants that had the heterozygous constitution just described or on tester plants crossed by such Spm-carrying heterozygotes (Fedoroff and Banks 1988). In all cases, only one of the parents contained an Spm element, whereas the other parent was homozygous for either a stable $a$ or the $a-m 1-5719 A 1 d S p m$ allele of the $a$ locus, as well as homozygous for a stable sh2 allele. In crosses to introduce a trans-activating $S p m-w$ element, one parent had the homozygous constitution $a-m 5-S p m-w s h 2$, whereas the other parent was an Spm-carrying heterozygote of the constitution described above (Fedoroff and Banks 1988). The a-m5-Spm-W allele has an $S p m-w$ insertion at a site within the coding region of the $a$ gene, and the element's restriction pattern is similar to that of an Spm-s element (McClintock 1962, 1963; Fedoroff and Banks 1988; J.A. Banks, unpubl.).

\section{DNA extraction and blot hybridization}

DNA was extracted from 4- to 6-week-old plants by the method of Shure et al. (1983) or Dellaporta et al. (1985), modified by the addition of a CsCl banding step. Genomic DNA was digested with restriction endonucleases, as specified by the supplier (Boehringer-Mannheim, Bethesda Research Laboratories, IBI, and New England Biolabs). Between 30 and 50 units of enzyme were used to digest $6 \mu \mathrm{g}$ of DNA. Initially, DNA was isolated and analyzed from 5 to 10 plants with an inactive programmable element, 4 plants with an active element, and 4 plants with a cryptic element. If a methylation-sensitive restriction enzyme had more than one site in the Spm element and adjacent $a$ gene, several digests were performed to determine the methylation status of each individual restriction site. Each sample was digested with two or three restriction enzymes, one or two of which were insensitive to methylation and the other of which was sensitive to methylation. Interpretation of the methylation state of a given restriction site was based on the outcome of blot hybridization analysis of all digests. Ambiguities in interpretation arose due to the fact that most of the plants used in the present studies were heterozygous at the $a$ locus and that there are several other sequences in the maize genome with substantial homology to the $a$ locus (T. Helentjaris, pers. comm.). To identify other fragments with homology 
to the probe used in a given experiment, DNA from plants that were homozygous for the $a$ allele on the homolog of the plant carrying the Spm element under study were included in all experiments to ensure the correct identification of DNA fragments derived from the homolog.

When it was essential to completely eliminate cross-hybridizing sequences, fragments of the appropriate size range to contain an Spm fragment were gel purified from genomic DNAs digested with a methylation-insensitive enzyme. The gel-purified fragments were then digested with a methylationsensitive enzyme, refractionated on an agarose gel, transferred to a nylon membrane, and hybridized to an a-gene or Spm probe. Once the overall pattern of methylation of restriction sites was established, DNA samples from additional plants were digested with appropriate pairs of methylation-insensitive and methylation-sensitive enzymes. Analyses were done on DNAs from 4 plants with an active element, 4 plants with an active programmable element, 12 plants with an inactive programmable element, 4 plants with an inactive programmable and an Spm-w element, 5 plants with a cryptic element, and 15 plants with a cryptic element and an Spm-w element.

Because certain restriction sites in genomic DNA from many of the plants were either partially or completely resistant to cleavage, internal controls for completeness of digestion were included in all experiments. These were done by incubating one tenth of each genomic DNA digest concurrently in a separate tube with a minute amount of ${ }^{32} \mathrm{P}$ end-labeled bacteriophage $\lambda$ or linearized pEMBL18 plasmid DNA. After a 2-hr incubation, the control samples were fractionated on an $0.5 \%$ agarose gel, which was then dried and exposed to X-ray film. The autoradiogram was examined for completeness of digestion of the labeled DNA prior to fractionation of the genomic DNA digest. If the labeled DNA in the control samples was completely digested, the genomic DNA digests were fractionated on agarose gels $(0.7-0.9 \%)$ and transferred to nylon membranes (GeneScreen Plus, NEN Research Products) by the alkaline transfer method (Reed and Mann 1985). The membrane was then hybridized with a cloned fragment of either the $a$ gene or the Spm element labeled to a sp. act. of at least $2 \times 10^{8} \mathrm{cpm} / \mu \mathrm{g}$ with [32P]dCTP by the random primer labeling method, as specified by the supplier (Amersham). The $a$-gene probe was $552 \mathrm{bp}$ in length and extended $72 \mathrm{bp}$ beyond the $3^{\prime}$ side of the element and 480 bp beyond the $5^{\prime}$ side of the element. The Spm probe was $1.7 \mathrm{~kb}$ in length and extended from nucleotide 267 to nucleotide 1963 of the element's 5' end. Hybridization was carried out as specified by NEN Research Products for nylon membrane filters.

DNA fragments were purified from agarose gels by mixing an equal volume of phenol with the macerated agarose gel slice, freezing the sample, extracting the resulting aqueous phase first with phenol, then with a $1: 1$ mixture of phenol and chloroform, and finally with chloroform alone, followed by ethanol precipitation of the DNA.

\section{RNA extraction and transcript analysis}

Total RNA was isolated from several individual plants of each genetic constitution, using $\sim 20 \mathrm{~g}$ tissue per sample, as described by Fedoroff (1985). Poly(A) ${ }^{+}$RNA was isolated by oligo(dT)-cellulose chromatography and fractionated on formaldehyde-agarose gels as described by Ausubel et al. (1987). The amount of RNA applied was standardized using a labeled cDNA fragment encoding the small subunit of RuBP carboxylase, kindly provided by N.-H. Chua of the Rockefeller University. RNA was transferred to GeneScreen (NEN), and the membrane filter was stained with methylene blue according to Herrin and Schmidt (1988) to detect the RNA. Prehybridization and hybridization was done according to Maniatis et al. (1982). Each blot was probed with a cDNA corresponding to the major Spm transcript, washed, and exposed to X-ray film. Radioactive probe was removed from the membrane by incubating the membrane four times in $0.01 \%$ SDS and $0.01 \times$ SSC. The membrane was then reprobed with the RuBP carboxylase cDNA to confirm that all of the RNA samples showed roughly equilivant hybridization intensities to the RuBP carboxylase probe. All probes were labeled to a sp. act. of $1 \times 10^{9} \mathrm{cpm} / \mu \mathrm{g}$ by the random-primer labeling method as described by the supplier (Amersham). Autoradiographic exposure to X-ray film was generally $16 \mathrm{hr}$.

\section{Acknowledgments}

We thank Jeff Kingsbury and George Rutherford for technical assistance and Bob Hoover of the Beltsville Agricultural Research Center of the U.S. Department of Agriculture for providing field space, preparation, and maintenance. This work was supported by fellowships to J.B. from the National Institutes of Health (NIH), P.M. from the Fonds National Belge de la Recherche Scientifique of Belgium, and by NIH grant 5-ROlGM34296-02.

\section{References}

Adams, R.L.P. and R.H. Burdon 1985. Molecular biology of DNA methylation. Springer-Verlag, New York.

Ausubel, F., R. Brent, R. Kingston, D. Moore, J. Seidman, J. Smith, and K. Struhl, eds. 1987. Current protocols in molecular biology. pp. 4.9.1-4.9.8. John Wiley and Sons, New York.

Bennetzen, J.L. 1985. The regulation of Mutator function and Mu transposition. UCLA Symp. Mol. Cell. Biol. 85: 343354.

Cedar, H. 1988. DNA methylation and gene activity. Cell 53: 3-4.

Chandler, V.L. and V. Walbot. 1986. DNA modification of a maize transposable element correlates with loss of activity. Proc. Natl. Acad. Sci. 83: 1767-1771.

Chomet, P.S., S. Wessler, and S.L. Dellaporta. 1987. Inactivation of the maize transposable element Activator $(A C)$ associated with DNA modification. EMBO J. 6: 295-302.

Coe, E.H., Jr. and M.G. Neuffer 1977. The genetics of corn. In Corn and corn improvement (ed. G.F. Sprague), pp. 111-223. American Society of Agronomy, Madison, Wisconsin.

Dellaporta, S., J. Wood, and J. Hicks. 1985. Maize DNA miniprep. In Molecular biology of plants. A laboratory course manual (instructors, R. Malmberg, J. Messing, and I. Sussex), pp. 36-37. Cold Spring Harbor Laboratory, Cold Spring Harbor, New York.

Fedoroff, N.V. 1985. Biochemical and molecular techniques in maize research. In Genetic engineering (ed. J.K. Setlow and A. Hollaender), vol. 7, pp. 115-133. Plenum Press, New York.

1986. Activation of Spm and Modifier elements. Maize Genet. Coop. Newslett. 60: 18-20.

- 1989. The heritable activation of cryptic Suppressormutator elements by an active element. Genetics, (in press).

Fedoroff, N.V. and J.A. Banks. 1988. Is the Suppressor-mutator element controlled by a basic developmental regulatory mechanism? Genetics (in press).

Fedoroff, N.V., J.A. Banks, and P. Masson. 1988a. Developmental determination of Spm expression. In Molecular basis of plant development (ed. R. Goldberg), Alan R. Liss, New York, (in press.) 
Banks et al.

Fedoroff, N., P. Masson, J. Banks, and J. Kingsbury 1988b. Positive and negative regulation of the Suppressor-mutator element. In Plant Transposable Elements (ed. D.E. Nelson!. Plenum Press, New York, (in press.)

Fedoroff, N., S. Wessler, and M. Shure. 1983. Isolation of the transposable maize controlling elements $A c$ and $D s$. Cell 35: 243-251.

Fowler, R.G. and P.A. Peterson. 1978. An altered state of a specific En regulatory element induced in a maize tiller. $G e$ netics 90: 761-782.

Gruenbaum, Y., T. Naveh-Many, H. Cedar, and A. Razin. 1981. Sequence specificity of methylation in higher plants. Nature 292: 860-862.

Herrin, D. and G. Schmidt. 1988. Rapid, reversible staining of Northern blots prior to hybridization. BioTechniques 292: $196-200$.

Holliday, R. 1987. The inheritance of epigenetic defects. Science 238: 163-170.

Kessler, C. and H.-J. Holtke. 1986. Specificity of restriction endonucleases and methylases-A review (edition 2). Gene 47: $1-153$.

Maniatis, T., E. Fritsch, and J. Sambrook. 1982. Molecular cloning. A laboratory manual, pp. 326-327. Cold Spring Harbor Laboratory, Cold Spring Harbor, New York.

Masson, P., R. Surosky, J.A. Kingsbury, and N.V. Fedoroff. 1987. Genetic and molecular analysis of the Spm-dependent a-m2 alleles of the maize $a$ locus. Genetics 177: 117-137.

Masson, P., K. Toohey, and N. Fedoroff. 1988. Excision of Spm in tobacco. Maize Genet. Coop. Newslett. 62: 26-27.

McClintock, B. 1951. Mutable loci in maize. Carnegie Inst. Wash. Yearb. 50: 174- 181.

- 1957. Genetic and cytological studies of maize. Carnegie Inst. Wash. Yearb. 56: 393-401.

- 1958. The Suppressor-mutator system of control of gene action. Carnegie Inst. Wash. Yearb. 57: 415-429.

- 1959. Genetic and cytological studies of maize. Carnegie Inst. Wash. Yearb. 58: 452-456.

- 1962. Topographical relations between elements of control systems in maize. Carnegie Inst. Wash. Yearb. 61: $486-493$.

1963. Further studies of gene-control systems in maize. Carnegie Inst. Wash. Yearb. 62: 486-493.

. 1965a. The control of gene action in maize. Brookhaven Symp. Biol. 18: 162-184.

- 1965b. Components of action of the regulators Spm and Ac. Carnegie Inst. Wash. Yearb. 64: 527-536.

- 1967. Genetic systems regulating gene expression during development. Dev. Biol. (suppl.) 1: 84-112.

-1971. The contribution of one component of a control system to versatility of gene expression. Carnegie Inst. Wash. Yearb. 70: 5-17.

Pereira, A., H. Cuypers, A. Gierl, Zs. Schwarz-Sommer, and H. Saedler. 1986. Molecular analysis of the $\mathrm{En} / \mathrm{Spm}$ transposable element system of Zea mays. EMBO I. 5: 835-841.

Peterson, P.A. 1966. Phase variation of regulatory elements in maize. Genetics 54: 249-266.

Raman, K., D.B. Walden, and R.I. Greyson. 1980. Propagation of Zea mays L. by shoot tip culture: A feasibility study. Ann. Bot. 45: 183-189.

Razin, A., H. Cedar, and A.D. Riggs. 1984. DNA methylation. Springer-Verlag, New York.

Reed, K. and D. Mann. 1985. Rapid transfer of DNA from agarose gel to nylon membranes. Nucleic Acids Res. 13: $7207-7221$.

Schwartz, D. 1988. Comparison of methylation of the male and female derived $w x-m 9 D s-c y$ allele in endosperm and sporo- phyte. In Plant Transposable Elements (ed. D.E. Nelson). Plenum Press, New York, (in press.)

Schwartz, D. and E. Dennis. 1986. Transposase activity of the Ac controlling element is regulated by its degree of methylation. Mol. Gen. Genet. 205: 476-482.

Schwarz-Sommer, Zs., N. Shepherd, E. Tacke, A. Gierl, W. Rhode, L. Leclercq, M. Mattes, R. Berndtgen, P.A. Peterson, and $H$. Saedler. 1987. Influence of transposable elements on the structure and function of the $A 1$ gene of Zea mays. EMBO I. 6: 287-294.

Shure, M., S. Wessler, and N. Fedoroff. 1983. Molecular identification and isolation of the Waxy locus in maize. Cell 35: $235-242$.

Walbot, V. 1988. Reactivation of the Mutator transposable element system following gamma irradiation of seed. Mol. Gen. Genet. 212: 259-264. 


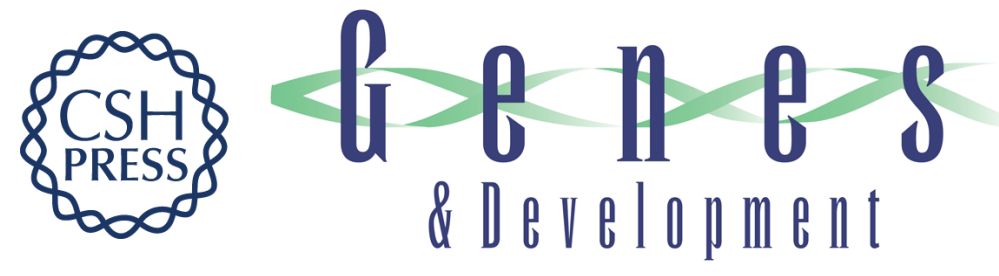

\section{Molecular mechanisms in the developmental regulation of the maize Suppressor-mutator transposable element.}

J A Banks, P Masson and N Fedoroff

Genes Dev. 1988, 2:

Access the most recent version at doi:10.1101/gad.2.11.1364

References This article cites 31 articles, 4 of which can be accessed free at:

http://genesdev.cshlp.org/content/2/11/1364.full.html\#ref-list-1

License

Email Alerting

Service

Receive free email alerts when new articles cite this article - sign up in the box at the top right corner of the article or click here.

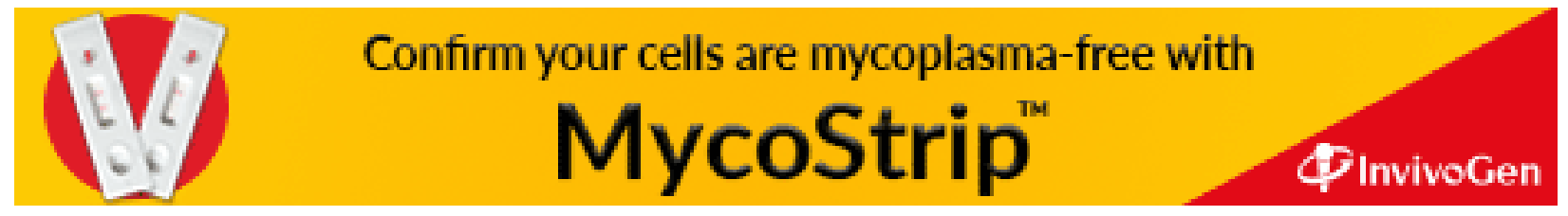

